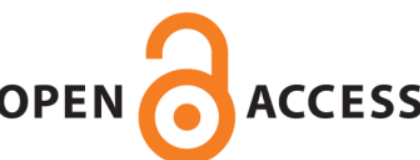

UWS Academic Portal

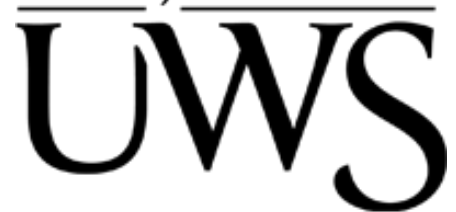

\title{
Modelling and performance analysis of different multilevel inverter topologies using PSO-MPPT technique for grid connected photovoltaic systems
}

Bounabi, Moussaab; Kaced, Karim ; Ait-Cheikh, Mohamed Salah ; Larbes, Cherif;

Dahmane, Zine elabadine; Ramzan, Naeem

Published in:

Journal of Renewable and Sustainable Energy

DOI:

$10.1063 / 1.5043067$

Published: 22/08/2018

Document Version

Peer reviewed version

Link to publication on the UWS Academic Portal

Citation for published version (APA):

Bounabi, M., Kaced, K., Ait-Cheikh, M. S., Larbes, C., Dahmane, Z. E., \& Ramzan, N. (2018). Modelling and performance analysis of different multilevel inverter topologies using PSO-MPPT technique for grid connected photovoltaic systems. Journal of Renewable and Sustainable Energy, 10(4), [043507].

https://doi.org/10.1063/1.5043067

\section{General rights}

Copyright and moral rights for the publications made accessible in the UWS Academic Portal are retained by the authors and/or other copyright owners and it is a condition of accessing publications that users recognise and abide by the legal requirements associated with these rights. 
This manuscript was accepted by Renewable Sustainable Energy. Click here to see the version of record.

\section{PublishiMgodelling and Performance Analysis of Different Multilevel Inverter Topologies}

2 Using PSO-MPPT Technique For Grid Connected Photovoltaic Systems.

\section{Moussaab BOUNABI, ${ }^{1}$ Karim KACED,${ }^{1}$ Mohamed.Salah AIT-CHEIKH, ${ }^{1}$} Cherif LARBES, ${ }^{1}$ zine elabadine DAHMANE, ${ }^{1}$ and Naeem RAMZAN ${ }^{2}$

1) Ecole Nationale Polytechnique, Electronic department, Algiers, ALGERIA.

2) University of the West of Scotland, School of Engineering and computing, Paisley, $U K$.

(Dated: 7 August 2018)

This paper proposes a new control structure for two multilevel three-phase inverter topologies for photovoltaic (PV) systems connected to the grid. This control scheme includes the use of the space vector pulse wide modulation (SVPWM) technique to control the Diode Clamped Inverter (DCI) and cascade inverter topologies, and the integration of the particle swarm optimisation (PSO) technique to operate the PV system at the Maximum Power Point (MPP). A FPGA implementation of PSO based MPPT is proposed to overcome the problem of MPP tracking under partial shading conditions. This MPPT technique is validated under various $P V$ array configurations in order to evaluate the behaviour of each $P V$ configuration under non-uniform irradiance. A SVPWM control strategy is used in order to generate gate control signals for the inverter and implemented for both DCI and cascade inverter topologies. Then, a comparative study of photovoltaic systems with these inverter topologies is carried out under Matlab/Simulink environment and evaluated on the basis of MPPT, harmonic distortion, cost, advantages and disadvantages. In order to test the practical implementation of the proposed control structure, FPGA/Simulink-based Hardware in the Loop approach has been used to bring the obtained results as close as possible to reality and with a minimum of constraints. Based on the analysis of the obtained results, some experimental parameters are summarized and a comparison table is synthesized.

Keywords: Photovoltaic systems, Multilevel inverters, PSO-MPPT, SVPWM, Gridconnected system 
Which energy sources will be suitable to power our smart cities in the future? With the wide use of an energetic mix by many countries because of the wide variety of fossil and renewable energy sources and the increasing demands in energy of modern applications, the conversion of energy between the source and the load is becoming an essential and crucial step in order to ensure adequate, high quality and efficient energy consumption. Renewable energy could play a vital role in the future by its integration in any powered system and at any level, from small home applications to big electrical power plants ${ }^{1-5}$. Among a variety of renewable energy sources, Photovoltaic (PV) energy is becoming a global issue as confirmed by Cop21 in their final declaration ${ }^{6}$. On the other hand, researchers and engineers are always eager to improve the efficiency of PV cells and PVinverters to develop high quality control techniques in photovoltaic systems stand-alone or connected to the grid, in order to improve the global efficiency of the energy conversion. Photovoltaic inverters are one of the essential elements in grid connected photovoltaic systems? ${ }^{7}$. They allow first the conversion of the photovoltaic generator DC voltage to an $\mathrm{AC}$ voltage and then the injection of this latter into the utility grid. The optimization of the energy production requires a suitable choice of the size and the type of inverters used.

In addition, PV inverters have other important functions when used in the context of connection to the utility grid such as:

- They optimize the efficiency of the PV installation by constantly looking for the MPP of the $\mathrm{PV}$ generator in relation to irradiation and temperature variations.

- They protect the PV installation against all potentially dangerous operating anomalies (voltage deviation, current leakage...) $)^{8}$.

The type of inverters to be used depends on the installation and connection parameters of the photovoltaic modules: connection in series or in parallel, different degrees of inclination between the modules, output voltage and solar irradiance. As a result of these technical features of photovoltaic systems, the arrays configuration and the architecture of PV systems connected to the grid can have important impacts on its operation ${ }^{9}$. Lot of research is carried out on PV system configurations, such as Pendem et al. ${ }^{10}$, Belhachet et al. ${ }^{11}$, Horoufiany et al. ${ }^{12}$. These researches involve the study and analysis of various photovoltaic panels settings 
Publishinger various partial shading scenarios, to assess the performance and ability of each setting 60 to increase output power and reduce partial shading losses. The PV system architecture depicts how the power converters are associated with PV modules. The circuit topology of the power inverters can be changed to additionally enhance the yield energy from grid connected PV system under partial shading conditions ${ }^{13}$. It allows the inverter to regularly reap more energy than a string-level or arrays level inverter ${ }^{14}$.

Grid connected PV inverter architectures normally have four conceivable settings: (a) central, (b) string, (c) multi-strings and (d) modular inverters. The central inverter topology, the most used one for its low cost and high productivity, is recommended in PV systems with a power greater than $10 \mathrm{~kW}^{15}$. Major disadvantages of this topology are the utilization of a high DC link voltage and one common MPPT. The string inverters topology, in contrast to the central inverter topology, comprises a separate MPPT at each string, leading to a maximum energy yield. Similarly, this topology has some drawbacks with the PV modules associated in series. In the modular inverter topology ${ }^{16}$, each module is fitted with its own MPPT and own inverter. The main weakness of the modular inverter configuration is its complex and costly control system. Mrilti-string inverter topology is a suitable setup ${ }^{17}$, situated somewhere between the modular inverter and the string inverter topologies. In this arrangement, each PV string can be controlled easily and separately.

Given the large body of work published on inverter topologies and MPPT techniques for shaded PV arrays, such us: Dhople et al. ${ }^{18}$, Roman et al. ${ }^{19}$, which proposed a micro-inverter architecture to implement MPPT for strings of solar cells associated through bypass diodes in a PV module. In Wu et al. ${ }^{20}$, another group of high-effectiveness DC/AC PV inverter with a variety of input DC voltage is proposed. A new scheme for a distributed synchronous boost convertér (DMPPT) is proposed by Adinolfi et al. ${ }^{21}$. A system utilizing an additional full bridge inverter to perform MPPT operation is provided by Debnath et al. ${ }^{22}$.

Different PV system architectures employing Power Conditioning Units (PCUs) with different technologies are developed by Spertino et al. ${ }^{23}$. Islam et al. ${ }^{24}$ proposed an improved H5, topology for grid connected photovoltaic inverter with reduced leakage current. Common mode $(\mathrm{CM})$ characteristics are studied in details. The drawback of this system is the cost of the small scale inverter. Control and circuit techniques to mitigate partial shading effects in photovoltaic arrays is presented by Bidram et al. ${ }^{25}$, a brief discussion of their characteristics and the approaches suggested in each category is provided. 
Publishing This paper proposes a new experimental study of photovoltaic system architectures con92 nected to the grid. In section 2, grid connected PV systems with their different PV modules configurations are presented and discussed. In section 3, PSO-MPPT control algorithm is developed and implemented into FPGA chip and tested under extreme partial shading scenarios. An experimental prototype for testing purposes has been implemented in this paper to determine which configuration extracts maximum power. In section 4 , the SVPWM algorithm for both cascade and diode clamped inverters are explained in details, including the duty cycles calculation, reference vector location and switching sequences generation. The control of the three-phase multilevel inverter through an LCL Filter is described. The FPGA implementation of the SVPWM algorithm with the Hardware in the Loop (HIL) approach is then proposed. Simulations and real time implementation results are given at the end of this section. Conclusion is given in section 5.

\section{PHOTOVOLTAIC SYSTEM ARCHITECTURES}

\subsection{Common DC sources (Centralized topology)}

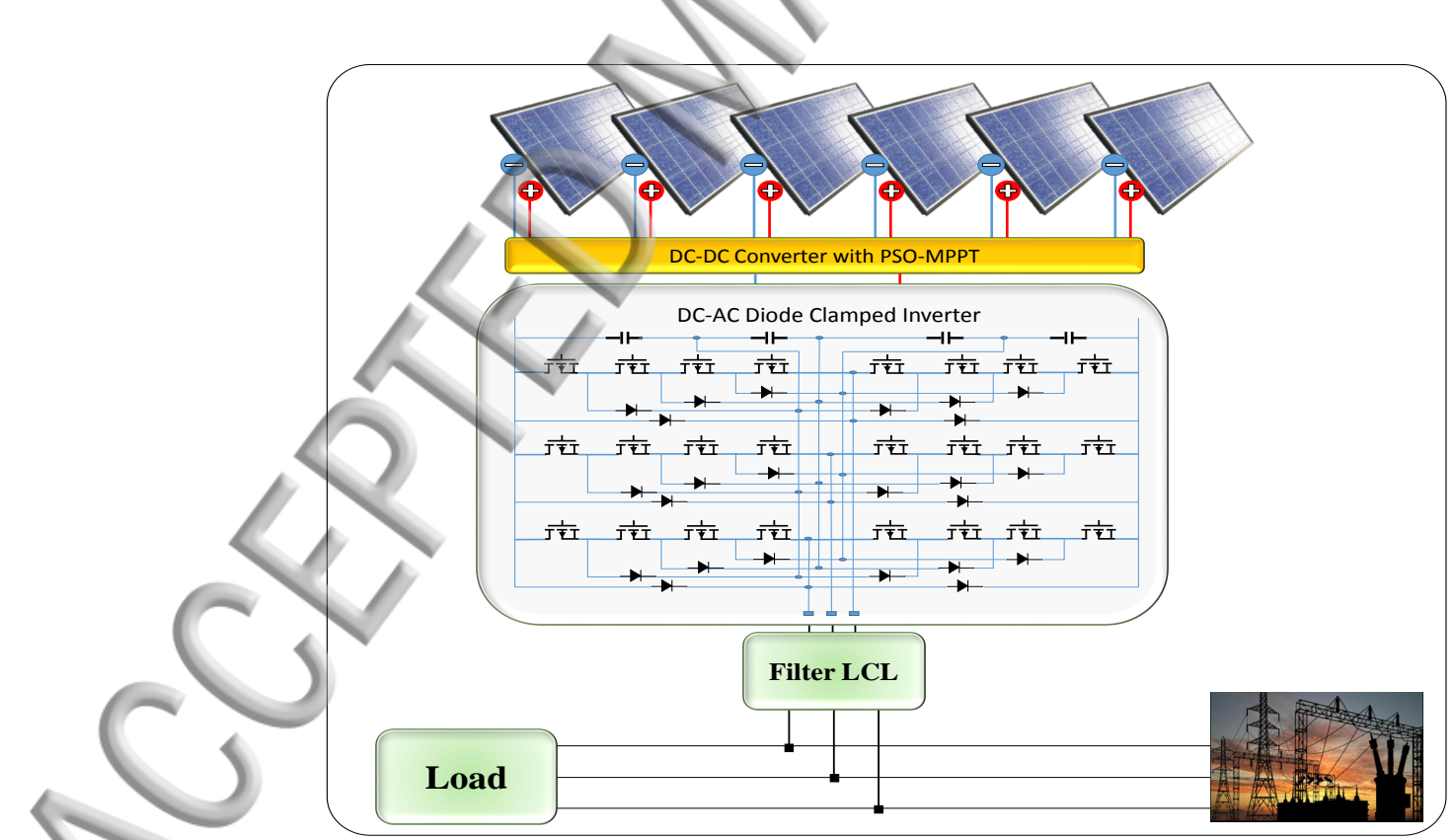

FIG. 1: Diode clamped inverter integrated with common DC sources (Centralized).

Central topology presented in Fig. 1 was based on centralized inverters (Diode clamped inverter) that interfaced a large number of PV modules to the grid. The PV modules 
Publishiwgre distributed into strings, each one producing the required high voltage to avoid further

amplification. Through string diodes, these strings were connected in parallel. A centralized system has many advantages in the case of projects with large homogeneous photovoltaic generators. Their watt-peak cost may be lower and maintenance can be facilitated because of the centralized setting. However, they still have some limitations such as high voltage in DC cables, power losses due to a centralized MPPT, mismatch losses between the PV modules and losses in the string diodes. Above a certain size of a PV installation, it becomes more practical to opt for a centralized topology in order to-avoid complications due to the use of a decentralized topology.

\subsection{Separate DC sources (Decentralized topology)}

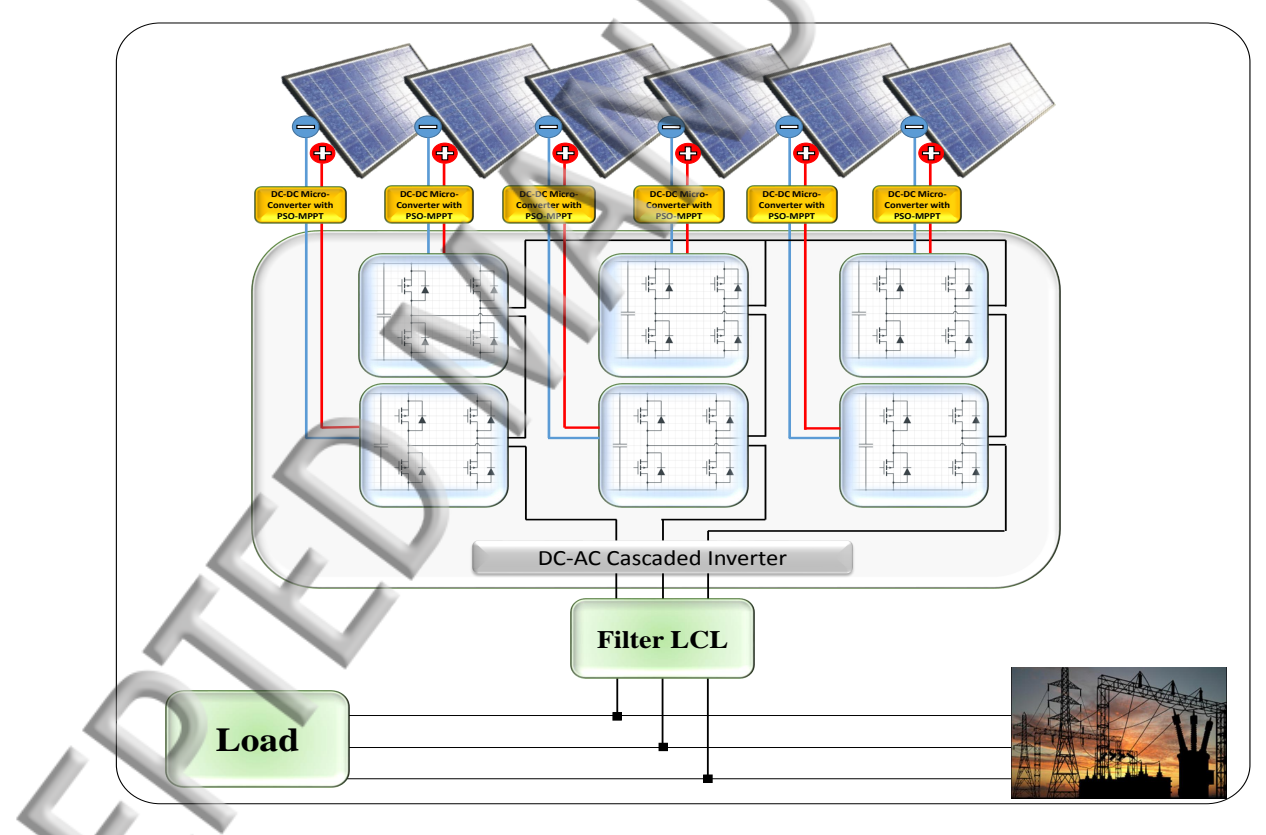

FIG. 2: Cascade inverter integrated with separate DC sources (Decentralized).

For Py installations with heterogeneous configurations such as different inclinations and orientations, modules and strings of different sizes, modules with high manufacturing tolerance or shaded modules, it is preferable to opt for decentralized concept using several DC-DC converters as shown in Fig. 2. With several DC-DC converters, it is possible to adapt to the different operating points of the various PV modules of the system. A string inverter is then connected with a series of PV modules with the same characteristics. The 
Publishingaracteristics of the PV modules are relatively constant, the modules are all more or less

different from each other. However, the yield of a string is directly dependent on the module having the lowest yield. So, if a module is partially shaded by tree leaves, dust or if it has a slight defect, the whole string will suffer. The use of a micro-converters can solve this problem as the PV modules are independent of each other. A module having a defect can also be disconnected while waiting to be cleaned or fixed without affecting the rest of the modules. The major disadvantage still faced by micro-converters is their cost. It is indeed obvious, that it is more costly to put one converter per $\mathrm{PV}$ module than one converter for 10 modules. Nevertheless, the cost can be competitive for complex installations which incorporate a monitoring system. Decentralized systems still have the option of replacing only one element in case of failure of one PV module or string or a drop in efficiency, while keeping the PV system in operation; thus redueing downtime and it is even better and more advantageous when using micro-inverters.

\section{DC-DC SIDE CONTROL FOR SHADED PHOTOVOLTAIC ARRAYS}

\subsection{PV module model}

In order to simulate the behaviour of the solar cell, the two-diode model equivalent circuit of a PV cell, shown in Fig. 3, is used. The PV module is composed by $N_{S} \mathrm{PV}$ cells associated in series. The output current of the PV module is described by Eq. $(1)^{26}$.

$$
I=I_{P V}-I_{01}\left[\exp \left(\frac{V+I R_{s} N_{s}}{a_{1} V_{T} N_{s}}\right)-1\right]-I_{02}\left[\exp \left(\frac{V+I R_{s} N_{s}}{a_{2} V_{T} N_{s}}\right)-1\right]-\left(\frac{V+I R_{s} N_{s}}{R_{p} N_{s}}\right)
$$

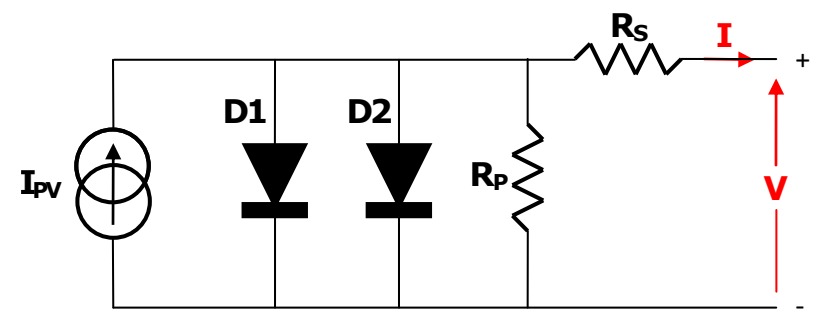

FIG. 3: Equivalent circuit of a solar cell.

where I and V refer respectively to the current and the voltage of the PV module. The $\mathrm{PV}$ module, SM55, is used in this paper. The parameters of this module under the standard 
Publishingt conditions (STC) $\left(T=298^{\circ} \mathrm{K}\right.$ and $\left.G=1000 \mathrm{~W} / \mathrm{m}^{2}\right)$ are given in Table I.

TABLE I: SM55 module specifications

\begin{tabular}{|l|c|}
\hline Parameters & Value \\
\hline Maximum power $\left(P_{\text {max }}\right)$ & $55 \mathrm{~W}$ \\
\hline Short circuit current $\left(I_{s c}\right)$ & $3.45 \mathrm{~A}$ \\
\hline Open circuit voltage $\left(V_{o c}\right)$ & $21.7 \mathrm{~V}$ \\
\hline Current at $P_{\text {max }}\left(I_{m p p}\right)$ & $3.15 \mathrm{~A}$ \\
\hline Voltage at $P_{\text {max }}\left(V_{m p p}\right)$ & $17.4 \mathrm{~V}$ \\
\hline Temperature coefficient of $I_{s c}\left(K_{I}\right)$ & $1.2 \times 10-3 \mathrm{~A} / \mathrm{AA} \hat{A}^{\circ} \mathrm{C}$ \\
\hline Temperature coefficient of $V_{o c}\left(K_{V}\right)$ & $-77 \times 10-3 \mathrm{~V} / \mathrm{AA}{ }^{\circ} \mathrm{C}$ \\
\hline Number of series cells in the module $\left(N_{s}\right)$ & 36 \\
\hline Number of bypass diodes & 2 \\
\hline
\end{tabular}

\subsection{Influence of partial shading}

Under uniform irradiance conditions, the PV module exhibits a single MPP. However, when a part of the PV module receives different levels of irradiance from those of others due to many factors such: buildings, clouds, trees, dust, then it is subject to partial $\operatorname{shading}^{27}$. The shaded PV cells may get reverse biased and behave as a loads receiving current from the fully illuminated cells which causes hot spot phenomenon that results in the damage of these cells. To resolve this problem, by-pass diodes are used. As a result, the P-V characteristics curves exhibit several MPPs when the PV module is subject to partial shading.

The P-V curve is then characterized by one global MPP (GMPP) and several local MPP (LMPP). Fig. 4(a) shows a PV array containing of two modules connected in series. Fig. 4(b) shows the corresponding static P-V characteristic curves for two different shading patterns. For the first case, the PV panel receives a uniform solar irradiance, thus, the P-V curve exhibits one MPP. In the second case, the tracking of the GMPP becomes a more challenging task, we can notice the appearance of four MPPs whose GMPP is $P=52,89$ $\mathrm{W}$ at $V=27.59 \mathrm{~V}$. Thus, the $\mathrm{P}-\mathrm{V}$ characteristic can take various forms according to the shading pattern. 


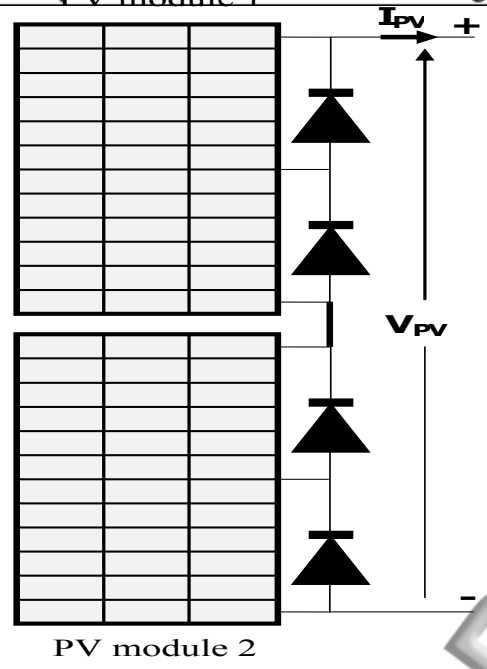

(a)

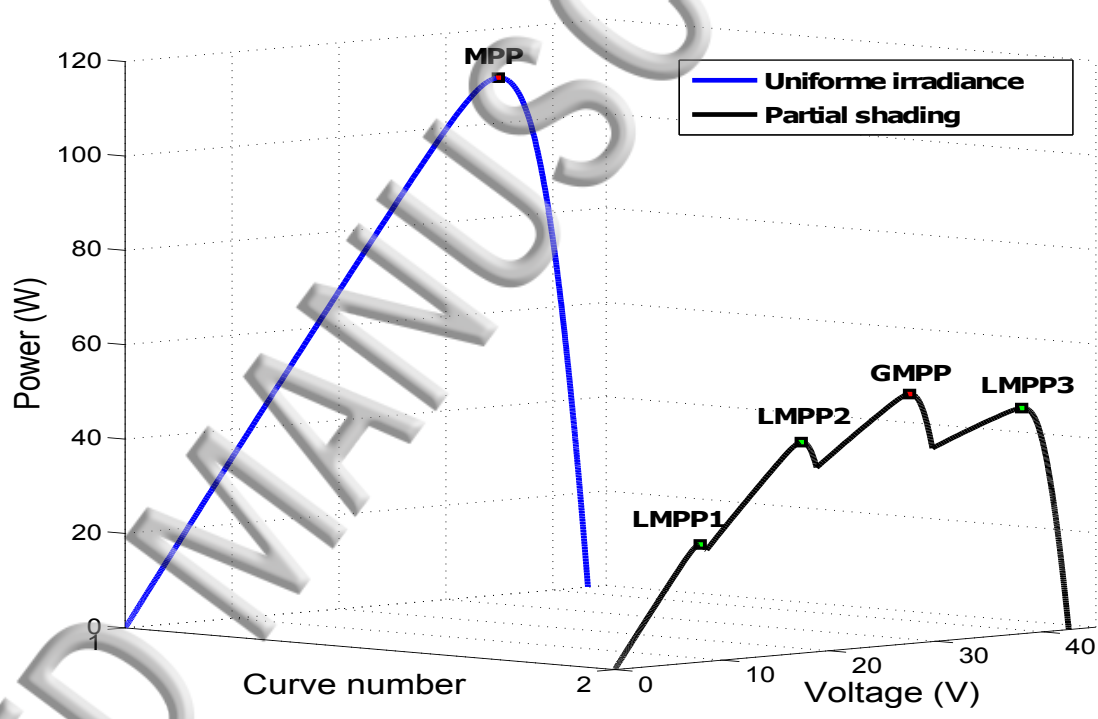

(b)

FIG. 4: (a): Two PV modules associated in series; (b): The P-V curves of the Two PV modules under uniform and partial shading conditions.

\subsection{MPPT controller based on PSO algorithm}

Several conventional MPPT algorithms have been proposed in the literature ${ }^{28}$. These methods are efficient under uniform conditions; however, they are limited under partial shading conditions. They cannot differentiate between LMPP and GMPP and can be trapped into a LMPP. To overcome this problem, methaheuristic algorithms are increasingly taken into consideration and are proposed by numerous scientists to manage multimodal P-V characteristic curves under partial shading conditions ${ }^{29-31}$. Thanks to its ability to handle 
Publishimg timodal functions and its simple structure, the particle swarm optimisation (PSO) based

MPPT is used in this paper. PSO is a population-based meta-heuristic approach that was developed by Eberhart and Kennedy in $1995^{32}$. The PSO algorithm is inspired by the social behaviour of swarming animals, such as bird flocking and fish schooling. Each particle in the swarm is considered as an answer of the issue and it is allocated a velocity and a position. Each particles velocity is influenced by the particles own-experience as well as the experience of its neighbors. For the application of the PSO algorithm in MPPT, the optimization variable to be taken into account is the duty cycle of the PWM signal (the particle position) and it is adjusted directly by the MPPT controller. Fig. 5 shows the complete flowchart of the proposed PSO-MPPT method. Initially, a first duty cycle solution vector with $N_{p}=3$ particles is defined. Maximizing the power output of the PV panel is the goal of the optimization process, which is the fitness function. Using Eq. (2) and Eq. (3), the new duty cycles are then updated for each iteration.

$$
\begin{gathered}
V_{i}^{k+1}=\omega V_{i}^{k}+c_{1} r_{1}\left(d_{\text {pbesti }}-d_{i}^{k}\right)+c_{2} r_{2}\left(d_{\text {gbest }}-d_{i}^{k}\right) \\
d_{i}^{k+1}=d_{i}^{k}+V_{i}^{k+1}
\end{gathered}
$$

where $w$ is the inertia coefficient; $c_{1}$ and $c_{2}$ are the acceleration coefficients; $r_{1}$ and $r_{2}$ are uniformly distributed random numbers in $[0,1]$ for each iteration t. $d_{\text {pbesti }}$ is the personal best position of particle $\mathrm{i}$ and $d_{g b e s t}$ denotes the best position reached by the particles of the swarm. The condition shown in the Eq. (4) is used as a convergence criterion.

$$
\left|d_{i}^{k+1}-d_{j}^{k+1}\right| \leq \Delta d
$$

Due to varying weather and loading conditions, the global MPP is usually changing. The MPPT algorithm should be able to continuously distinguish the variety of shading configuration and search for the new global MPP. The search procedure is initialized when the following condition (Eq. (5)) is met.

$$
\frac{\left|P_{\text {PVnew }}-P_{\text {PVlast }}\right|}{P_{\text {PVlast }}}>\Delta P
$$

where $P_{P V \text { new }}$ and $P_{P V \text { last }}$ are the values of PV power in two successive sample periods and $\Delta P$ presents the power tolerance. 


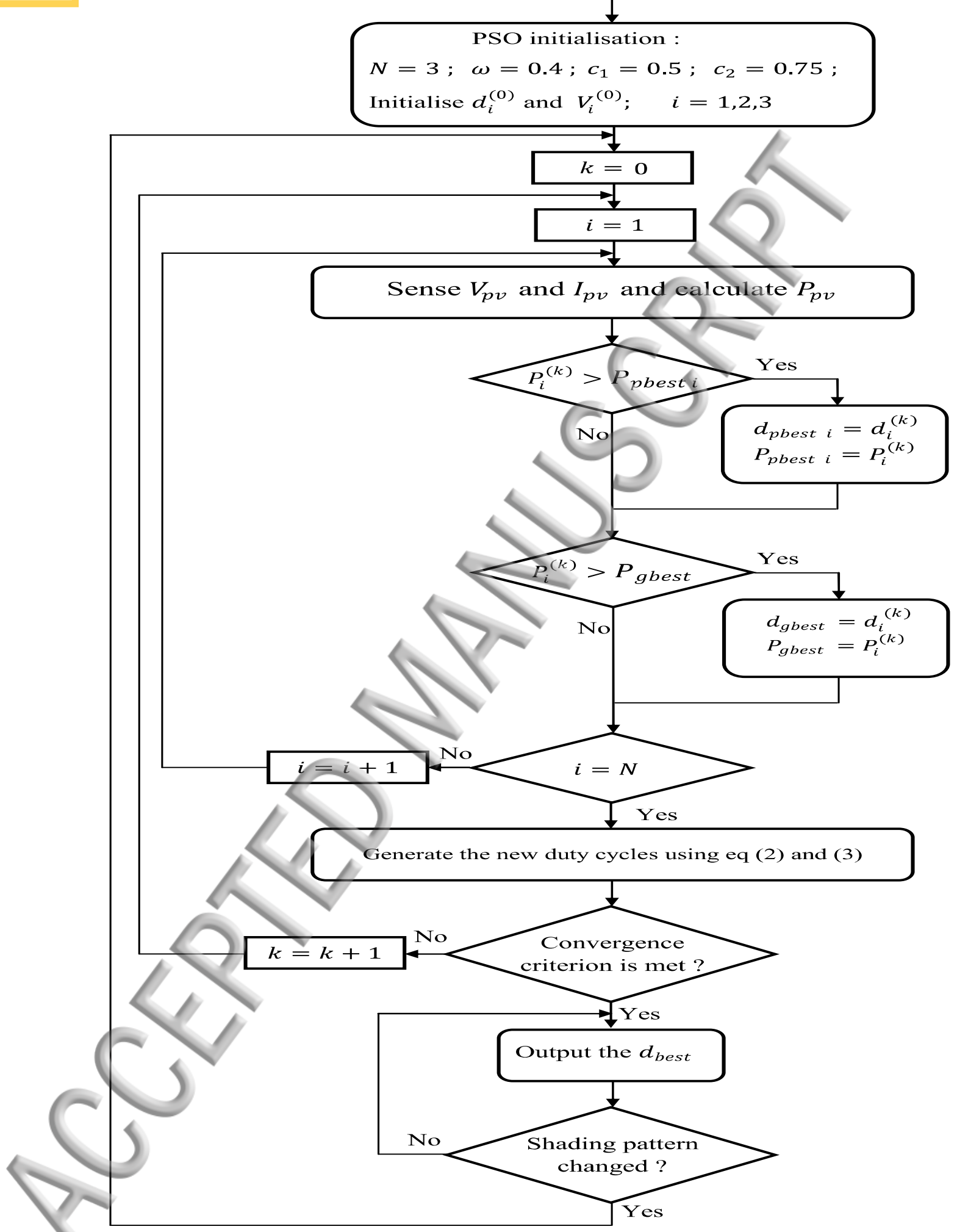

FIG. 5: Complete flowchart of the proposed PSO-MPPT method. 


\section{Experimental implementation of PSO-MPPT under different topologies}

In order to select the optimal PV systems architectures and circuit topologies offering the highest performance and to evaluate the behaviour of each $\mathrm{PV}$ inverter setting due to non-uniform irradiation, we performed tests under different shading scenarios for two PV architectures: string and modular. A FPGA-based control circuit prototype, shown in Fig. 6, was developed for this purpose. The schematic prototype of the first considered PV system architecture, string architecture, is shown in Fig. 7(a). The experimental results obtained for this topology under two scenarios of partial shading are shown in Figs. 9 and 10. The resulted P-V curves are characterized by the presence of multiple MPPs: for scenario 1: $P_{L M P P}=31.9 \mathrm{~W}$ and $P_{G M P P}=49.6 \mathrm{~W}$. and for scenario $2: P_{L M P P 1}=25 \mathrm{~W}$ and $P_{G M P P}=81.7 \mathrm{~W}$. The GMPP is on the left of the P-V curve for the two scenarios, with $V_{G M P P}=23.8 \mathrm{~V}$ in scenario1 and $V_{G M P P}=43.5 \mathrm{~V}$ in scenario 2 . It can be seen that the PSO algorithm has effectively found the GMPP in the two cases and the operating point is maintained around $V=23.8 \mathrm{~V}$ and $T=2.1 \mathrm{~A}$ in scenario 1 and $V=43.5 \mathrm{~V}$ and $I=1.87 \mathrm{~A}$ in scenario 2.
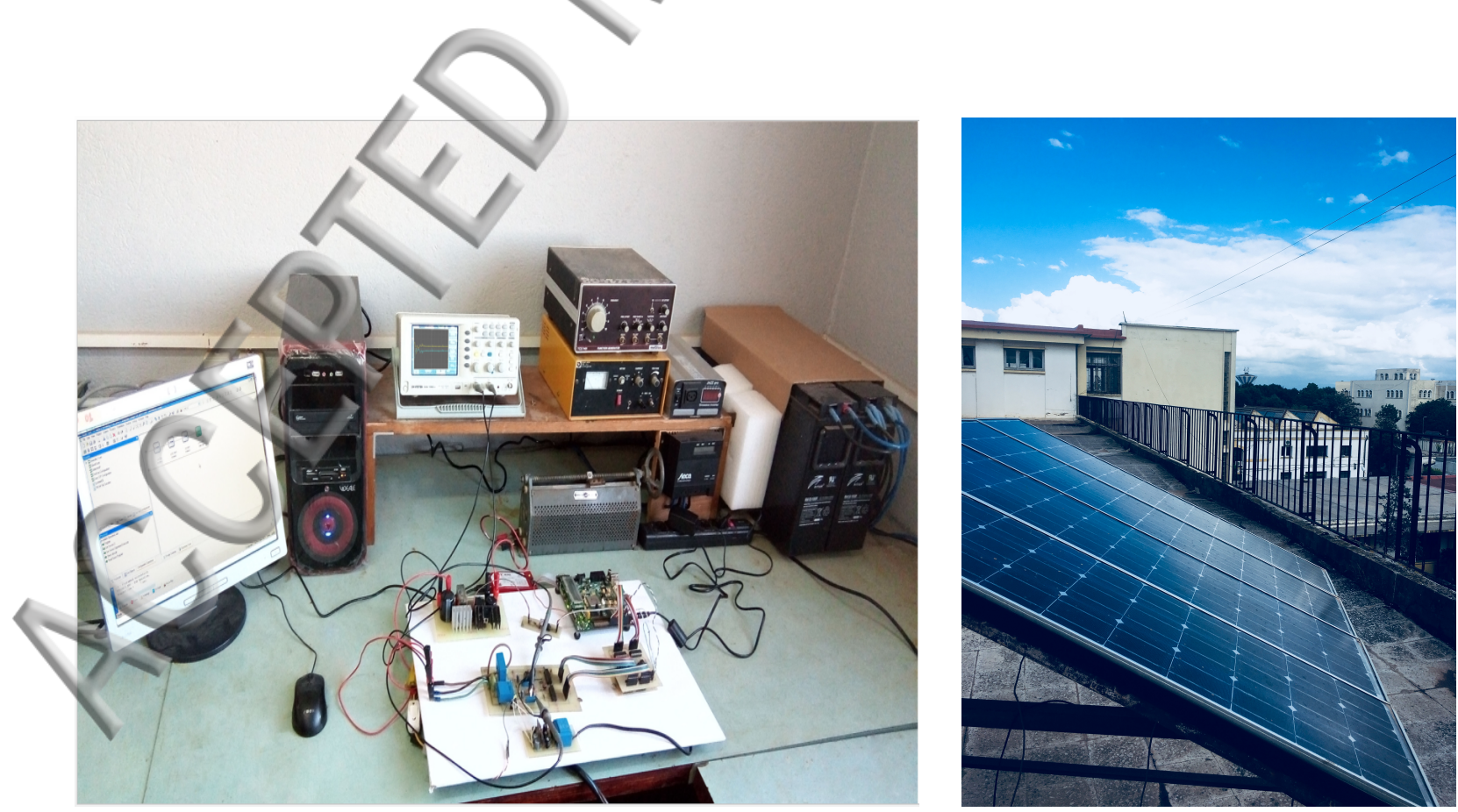

FIG. 6: Components of PV system under test. 
Module 1
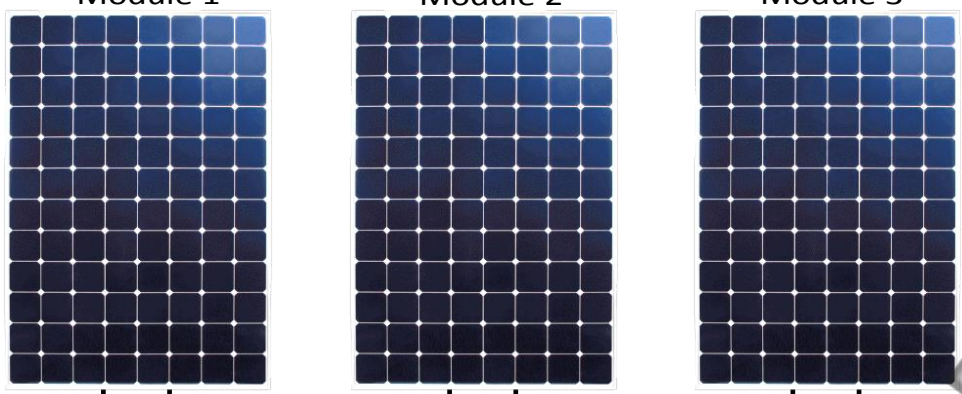

Module 4
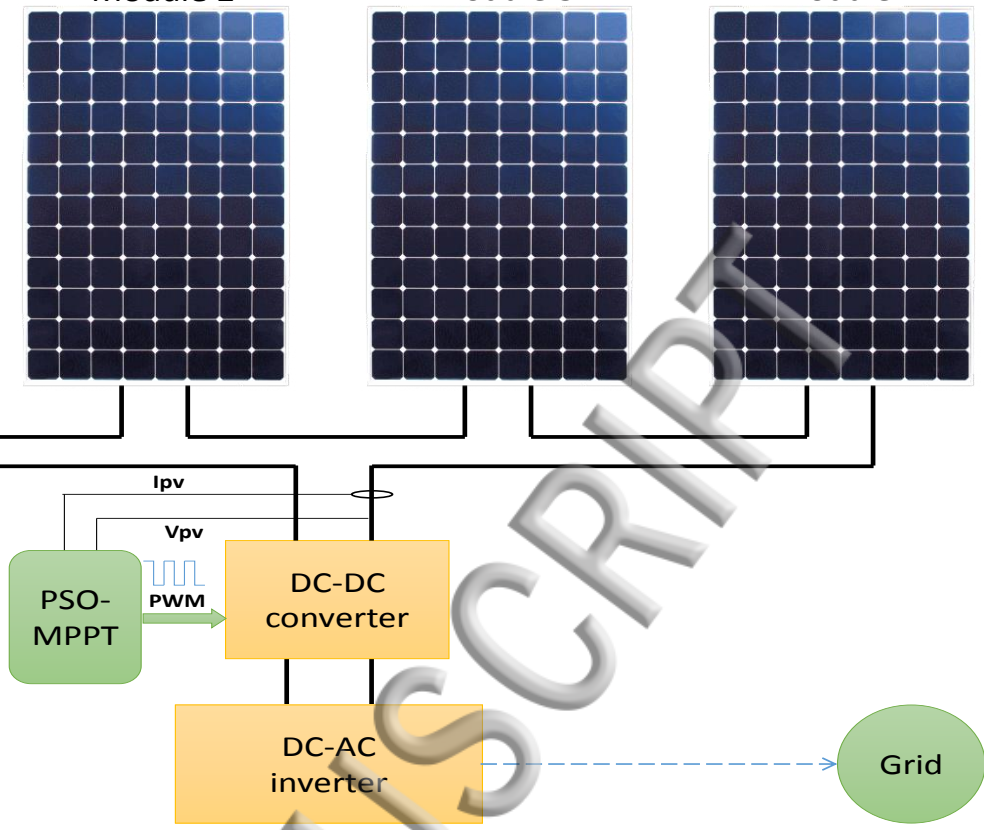

(a)
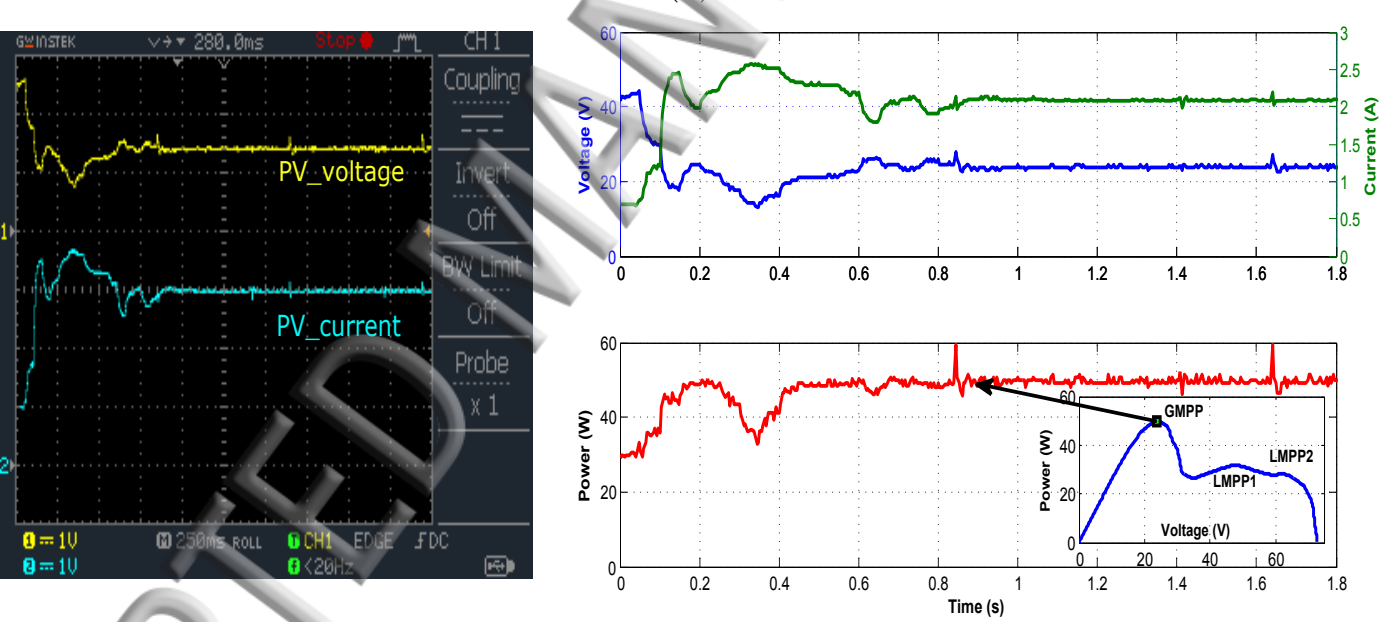

(b)

FIG. 7: (a): Schematic prototype of the proposed central architecture control;

(b): Measured array voltage, current and power waveforms during MPPT process under a shading pattern.

The schematic prototype of the second considered PV systems architectures, modular architecture is shown in Fig. 8(a). The experimental results obtained for this topology under two scenarios of partial shading are shown in Figs. 9 and 10. This figures show the P-V curves for each separate PV module as well as the results of the MPP tracking. 


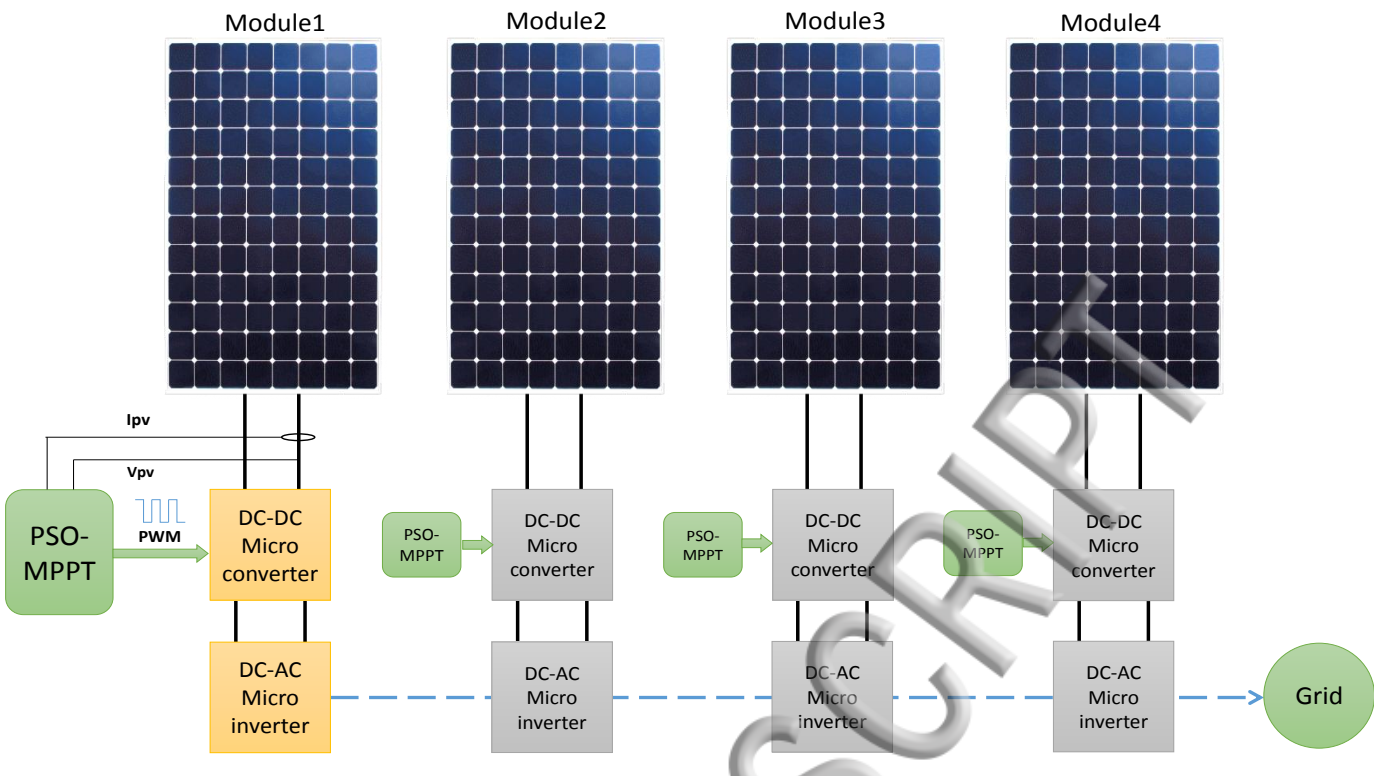

(a)
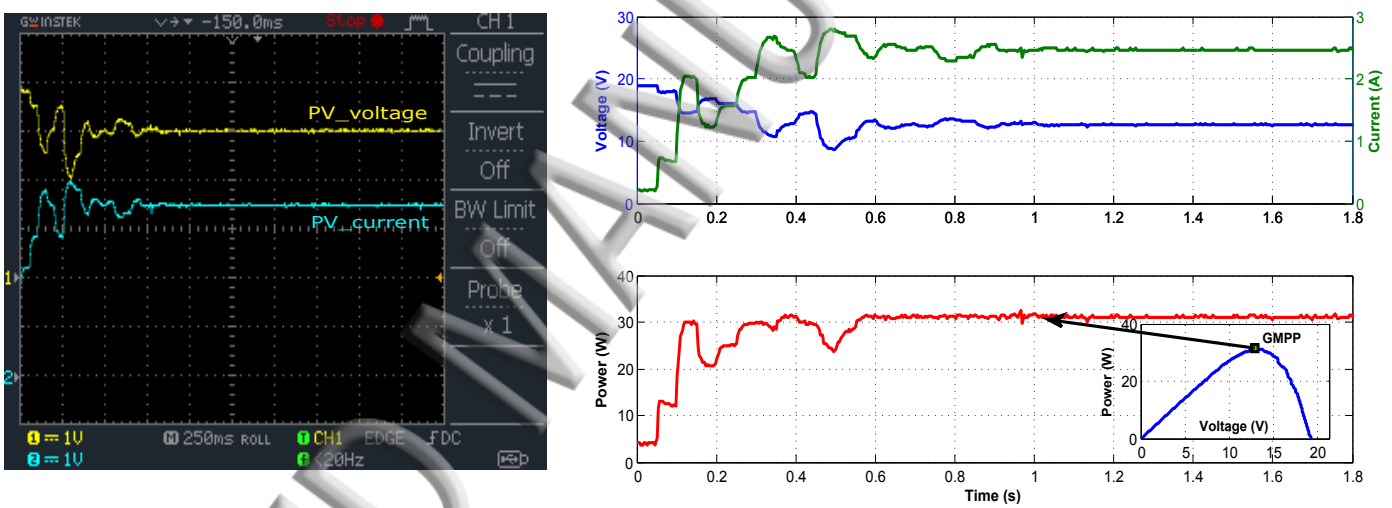

(b)
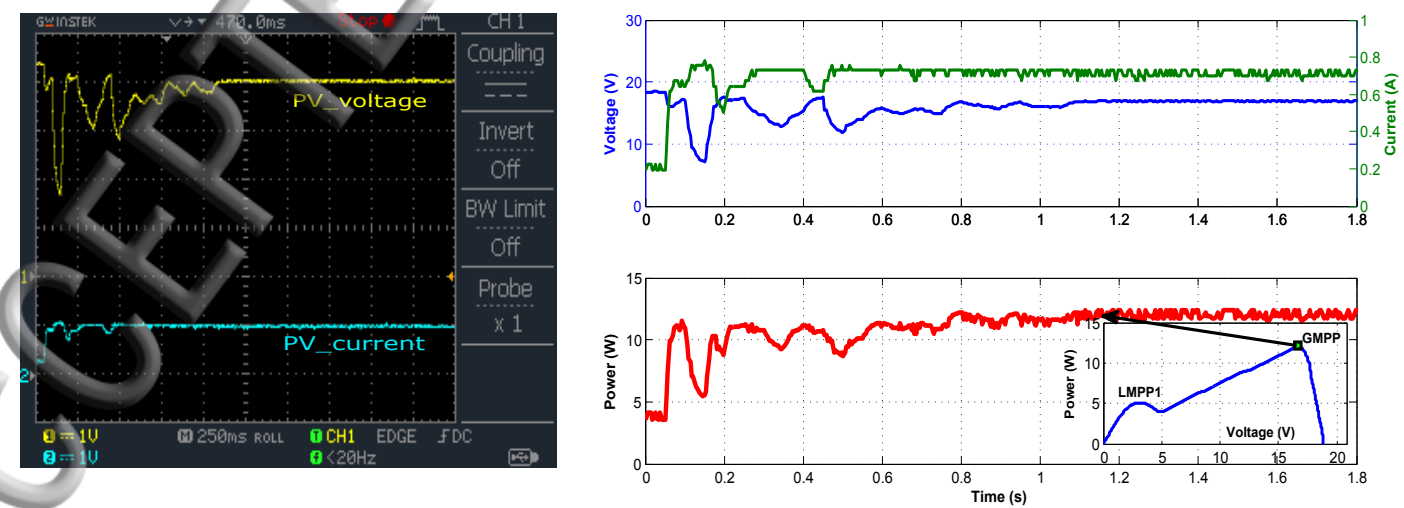

(c)

FIG. 8: (a): Schematic prototype of the proposed modular architecture control;

(b): Measured array voltage, current and power waveforms during MPPT process under a uniform pattern for module 1; (c): under shading pattern for module 2. 

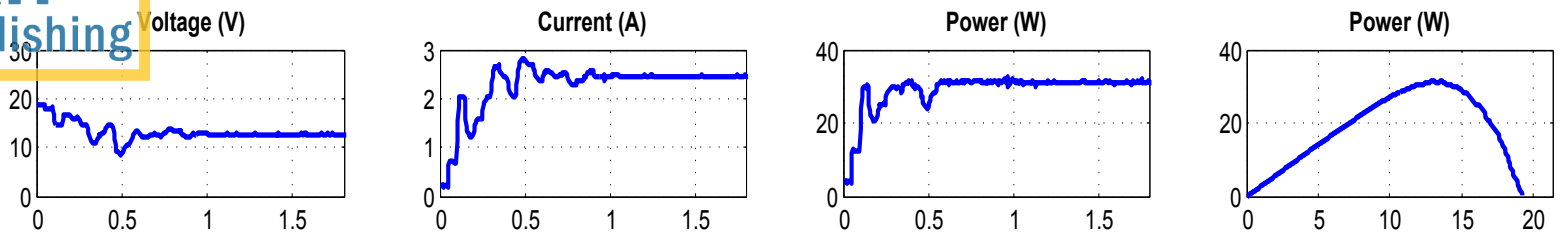

Module 1
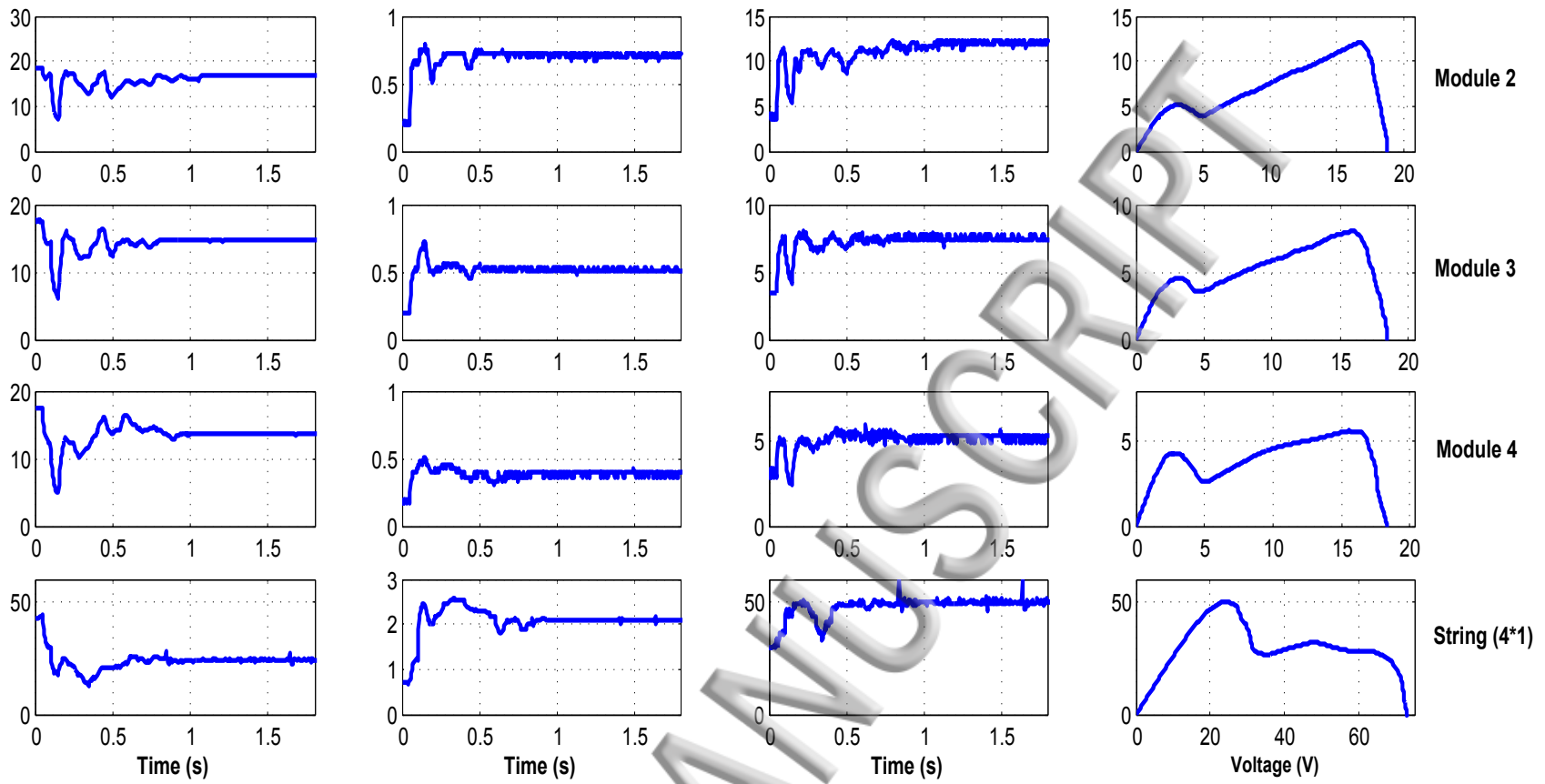

FIG. 9: Experimental waveforms under Irradiance Condition Scenario 1 (ICS1) containing (voltage, current, power and $P-V$ characteristic curve).

Considering the configurations of available photovoltaic system architectures: string, modular that has been examined under two possible shading scenarios, a detailed observation of Figs. 7 to 10 and the results shown in Table II, show that the performance of the PV generator is variable and the choice of the most optimal and appropriate configuration depends strongly on the shading pattern, the intensity of shading, the type of shading affecting the PV/array (uniform or not) and the used configuration. In order to obtain a practically usable voltage, it is essential to use a series connection of solar cells in an array. Since there is a considerable loss of power due to non-uniform illumination in a serial array, care must be taken to ensure that all cells associated in series get a similar irradiance under different shading patterns.

A number of these strings are connected in parallel to obtain the required power. Such care will give better protection to the grid and at the same time, the total energy production will be higher. 
Publishing voltage (V)
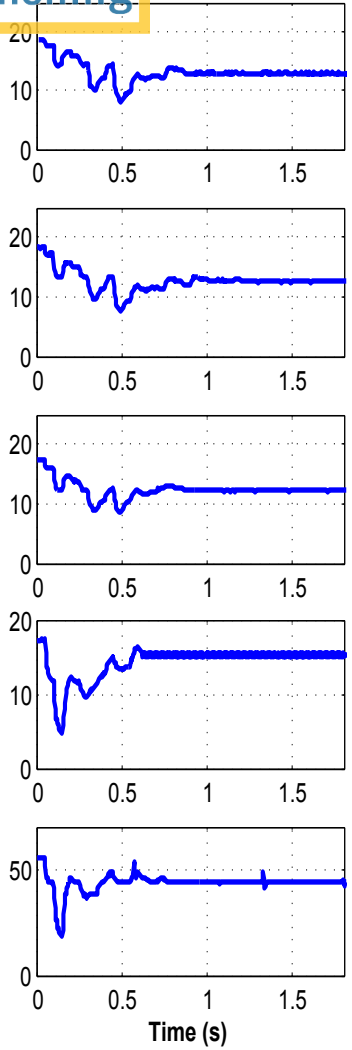
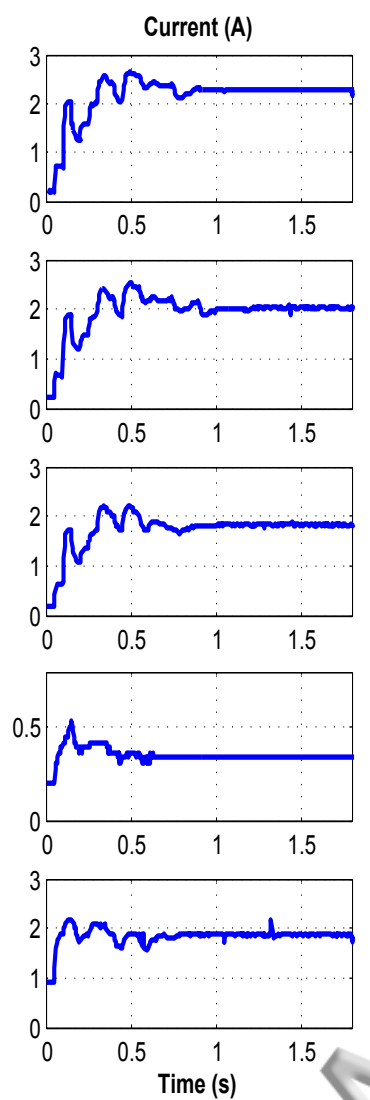
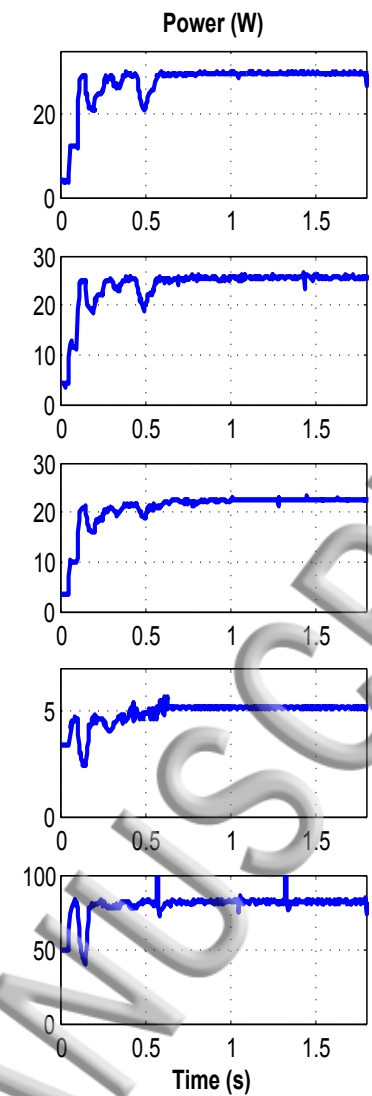
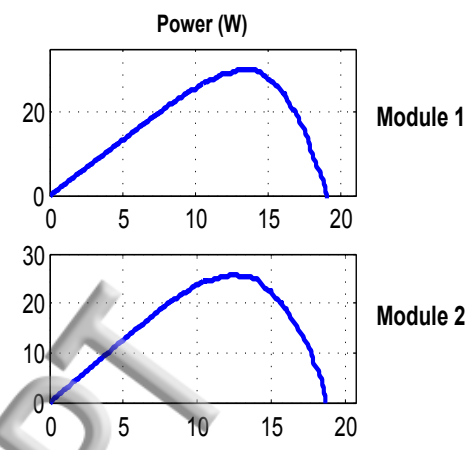

Module 2

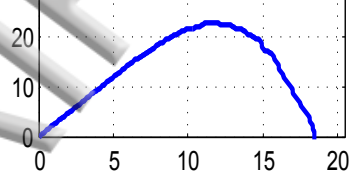

Module 3

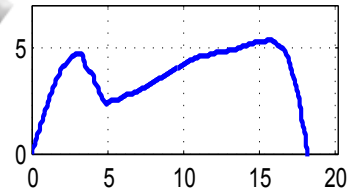

Module 4

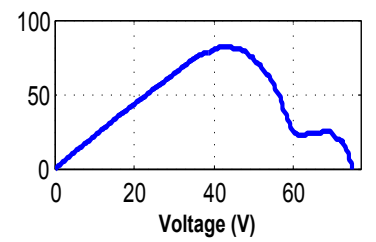

String $\left(4^{*} 1\right)$

FIG. 10: Experimental waveforms under Irradiance Condition Scenario 2 (ICS2) containing (voltage, current, power and $P-V$ characteristic curve).

TABLE II: Experimental results of a PV system architectures under two irradiance condition scenarios

\begin{tabular}{|c|c|c|c|c|c|c|}
\hline & \multicolumn{4}{|c|}{ scenario_1 } & \multicolumn{3}{c|}{ scenario_2 } \\
\cline { 2 - 7 } & Current(A) & Voltage(V) & Power(W) & Current(A) & Voltage(V) & Power(W) \\
\hline Module1 & 2.49 & 13.05 & 32.5 & 2.31 & 13.6 & 31.5 \\
\hline Module2 & 0.73 & 17.9 & 13.11 & 2.10 & 12.72 & 26.8 \\
\hline Module3 & 0.54 & 14.6 & 8 & 1.88 & 12.42 & 23.4 \\
\hline Module4 & 0.41 & 13.6 & 5.7 & 0.42 & 13.57 & 5.7 \\
\hline String(4S) & 2.10 & 23.8 & $\mathbf{4 9 . 6}$ & 1.8 & 43.52 & $\mathbf{8 1 . 7}$ \\
\hline Modular & \multicolumn{7}{|c|}{ maximum power extracted= 59.31W } & maximum power extracted= $\mathbf{8 7 . 4 W}$ \\
\hline
\end{tabular}


Publishing]n this paper, the string and modular connections are compared under different shaded patterns. In these conditions, it can be seen that the modular connection is dominant. The result show also the benefit of inserting an adaptation stage with PSO-based MPPT between the PV array and the load in order to optimize the produced power at any time. The choice of the PV inverter used to inject this power extracted into the grid/depends strongly on the architecture of the photovoltaic arrays used. The following section describes how the PV inverter converts and delivers the energy produced with maximum efficiency and safety into the grid.

\section{DC-AC SIDE CONTROL FOR PV INVERTERS CONNECTED TO THE GRID}

\subsection{Introduction}

The most widely known inverters to date are the two-stage inverters. These two-level inverters are limited in voltage and in power. In order to increase both of them, several inverters are usually connected in series or in parallel, resulting in a complex control and an increase in the cost of the system. In order to overcome these drawbacks, the multilevel conversion structures provide solutions by connecting power semiconductors in series ${ }^{33}$. There are three main topologies of multi-level inverters:

- Diode Clamped Inverter (DCI) which is a structure with common potential distribution as shown in Fig. 1. The five-level solution is presented in this paper.

- Multi-level inverters with nested cells, this structure requires separate DC voltages.

- Multi-level inverters in cascade as shown in Fig. 2. The five-level solution is also presented in this paper.

The adoption of these structures in industrial installations has been motivated by many advantages such as the reduction of the harmonic distortion rate, the improvement of the power factor, the minimization of the filtering quantities and the almost sinusoidal output voltage. 


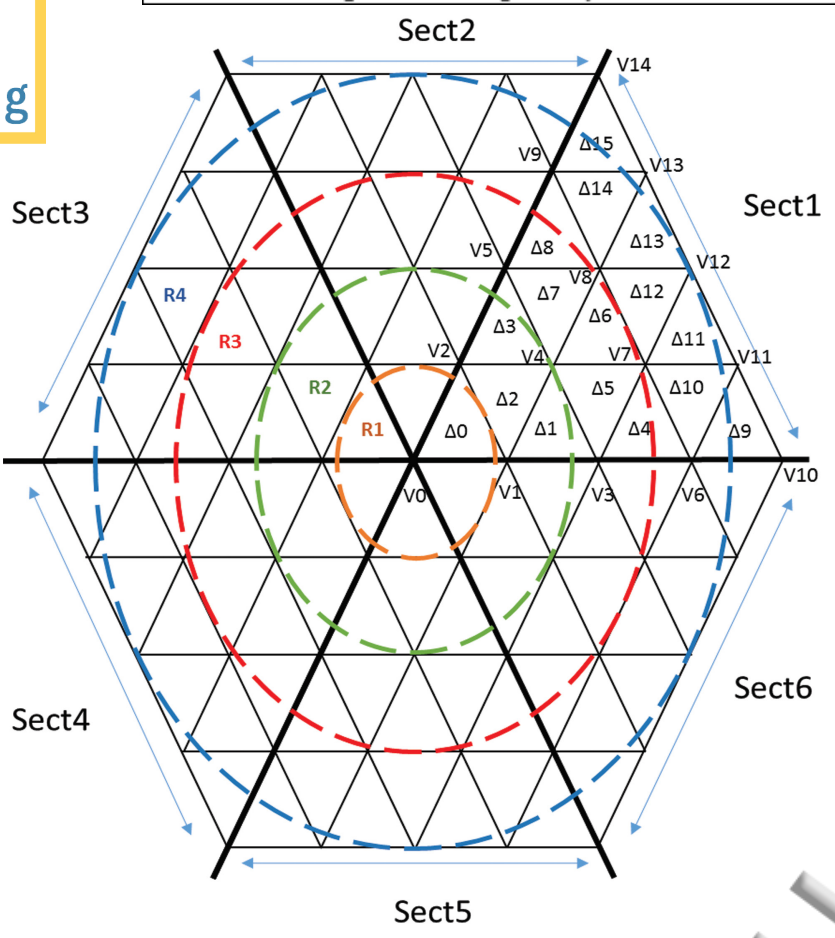

(A)

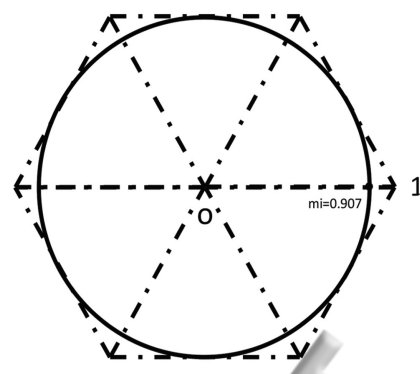

(a)

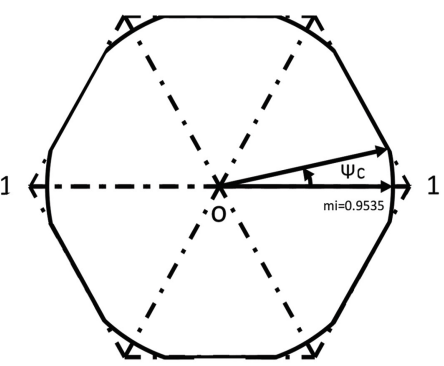

(b)

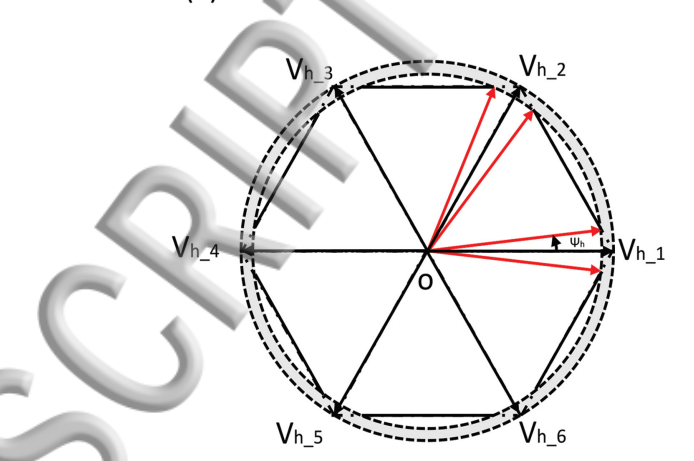

(c)

(B)

FIG. 11: (A): Space vector diagram for five-level inverter. (B): Modes of operation: (a):sinusoidal; (b):over-modulation I; (c):over-modulation II

\subsection{Control and modulation strategy based on the SVPWM}

Since, Bhagwat and Stefanovic ${ }^{34}$ who have first discussed the approach of the multilevel pulse width modulation (PWM) converter, various PWM strategies have been studied in details, developed and implemented ${ }^{35-37}$. PWM is widely used in Voltage Source Inverter (VSI), since variable frequency and variable voltage outputs can be obtained. Among all strategies, space vector modulation (SVPWM) outstand all the techniques because of its powerful compatibility to optimize switching waveform, switching pulse pattern, vector region selection and duty cycle calculation.

In this paper, SVPWM technique is developed in order to generate PWM control signals for the inverter. This technique has many advantages such as low power losses, higher DC bus efficiency, variable frequency and voltage magnitude control. SVPWM has also a wide linear modulation range, low computations and it is relatively easy to implement. Progress in processors has reduced the computation time and made the SVPWM almost the favoured PWM technique. 


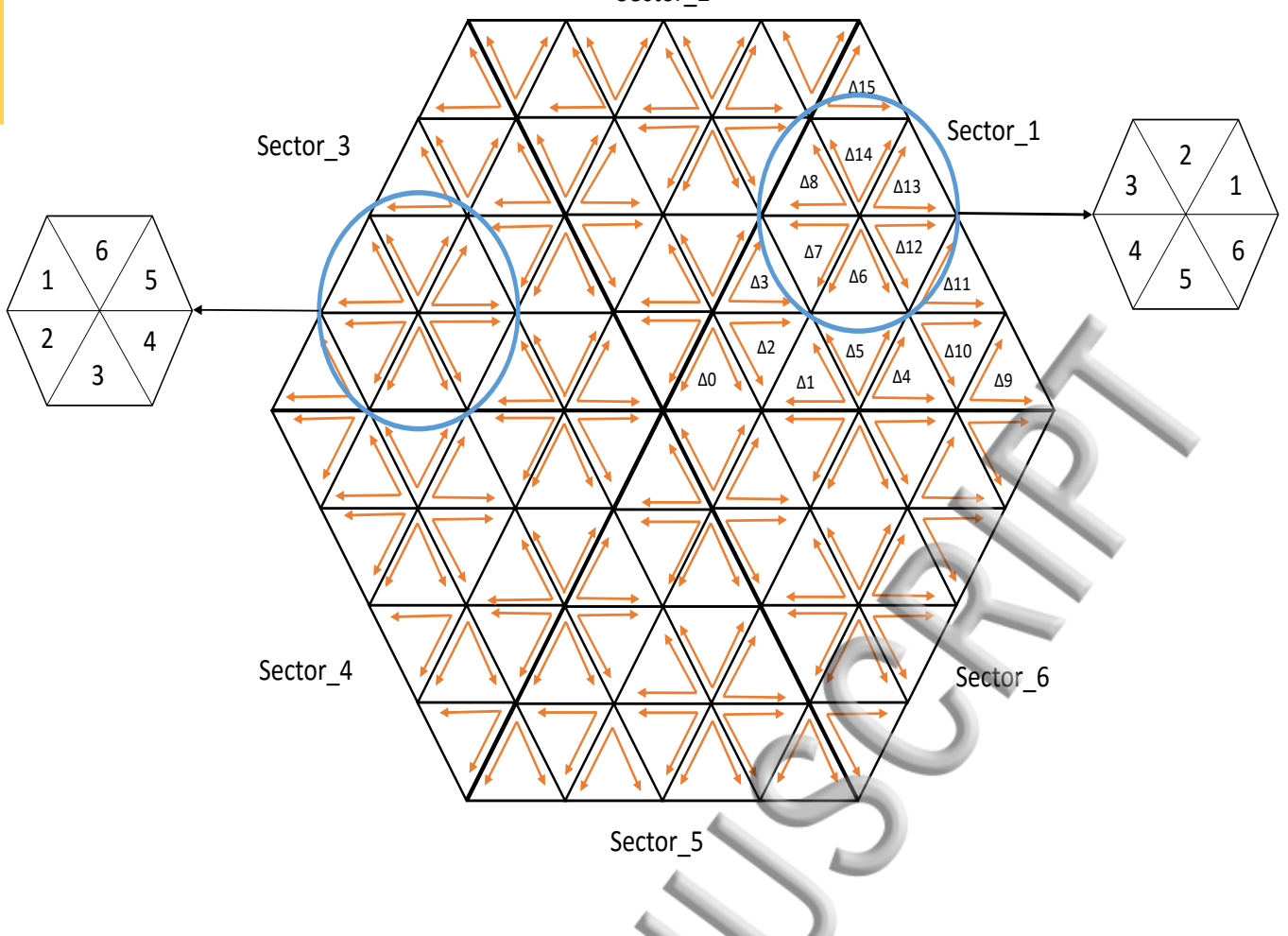

FIG. 12: Switching Sequence diagram for 5-level space vector PWM.

SVPWM scheme with an over-modulation mode for a multilevel inverter is proposed. The main objective of the SVPWM technique is to estimate the reference voltage vector $\left(V_{\text {ref }}\right)$ instantaneously by relating the switching states corresponding to the reference space vectors. More precisely, for every PWM period, the reference vector $\left(V_{r e f}\right)$ is averaged by using its two adjacent space vectors for some duration of time and a null vector for the rest of the period. In this paper, a switching sequence is elaborated using the common-mode voltage elimination ${ }^{34}$. Hence, for any triangle there could be numerous switching sequences. However, one and only one sequence can be executed at any switching time. An order is identified in Fig. 12 for each triangle in Fig. 11(A). The triangle in odd sectors $\left[S_{1}, S_{3}, S_{5}\right]$ has identical duty-ratios order. Also, the triangle in even sectors $\left[S_{2}, S_{4}, S_{6}\right]$ has identical duty-ratios order.

This structure has been applied to a five-level cascaded inverter and can be extended to several level inverters. The structure can be utilized for both cascaded H-bridge inverters and DCI topologies and can certainly be extended to include over-modulation range. Having determined the triangle $\Delta_{j}$, the shift vector $V_{r}$ is now calculated by following the switching sequences which vary from a triangle to another. For each triangle, we require an organization to order the on-times calculated $t_{a}, t_{b}, t_{o}$ in desired sequence of $\left[t_{0} \rightarrow t_{a} \rightarrow t_{b} \rightarrow t_{0}\right]$. 

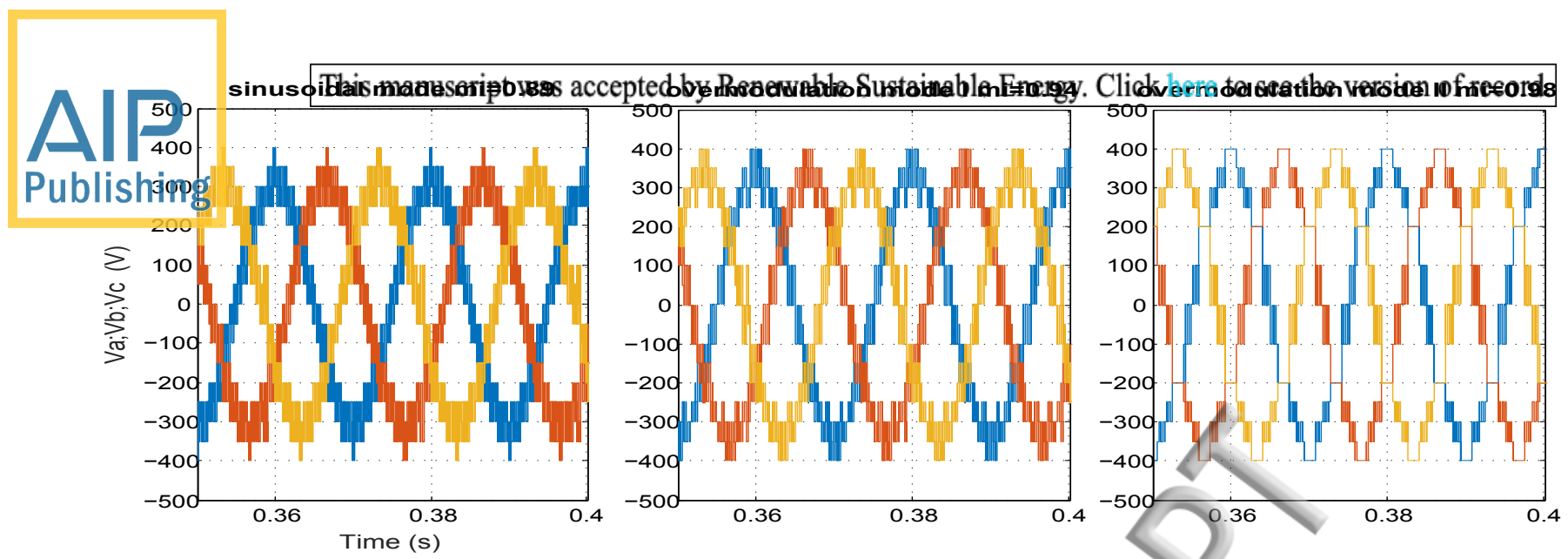

(a)
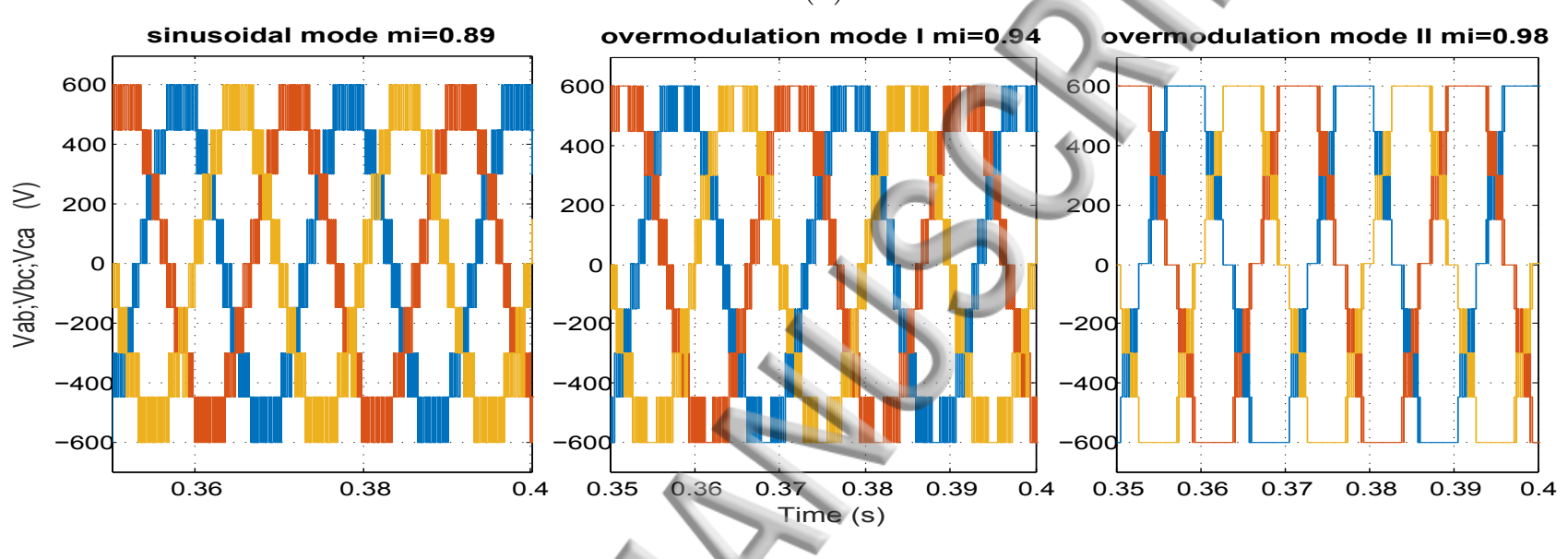

(b)

FIG. 13: Simulation results for inverter output line to neutral voltages (a): and line to line voltages (b): corresponding to sinusoidal mode; over-modulation I; over-modulation II.

\subsection{Simulation and experimental implementation of the SVPWM}

Based on Matlab/Simulink, several simulations were carried out to evaluate the control and synchronization algorithms. The SVPWM output is generated from the Simulink. The developed programs determine first the position of the reference vector according to the sampling frequency $f_{s}=5 \mathrm{kHz}$ and the fundamental frequency $f=50 \mathrm{~Hz}$. On the basis of the sector selected, where the reference vector is located, the switching sequence and the operating time for different switching states are computed. Fig. 13 illustrates the results of the output simulation in the case of a switching frequency of $5 \mathrm{kHz}$. Moreover and in order to check the feasibility of the SVPWM that has been depicted above, implementation on FPGA circuit is used to execute the proposed control. Fig. 14(a) represents the block diagram of the proposed VHDL program where $c l k$ is the input clock and $m i$ is the modulation index. 


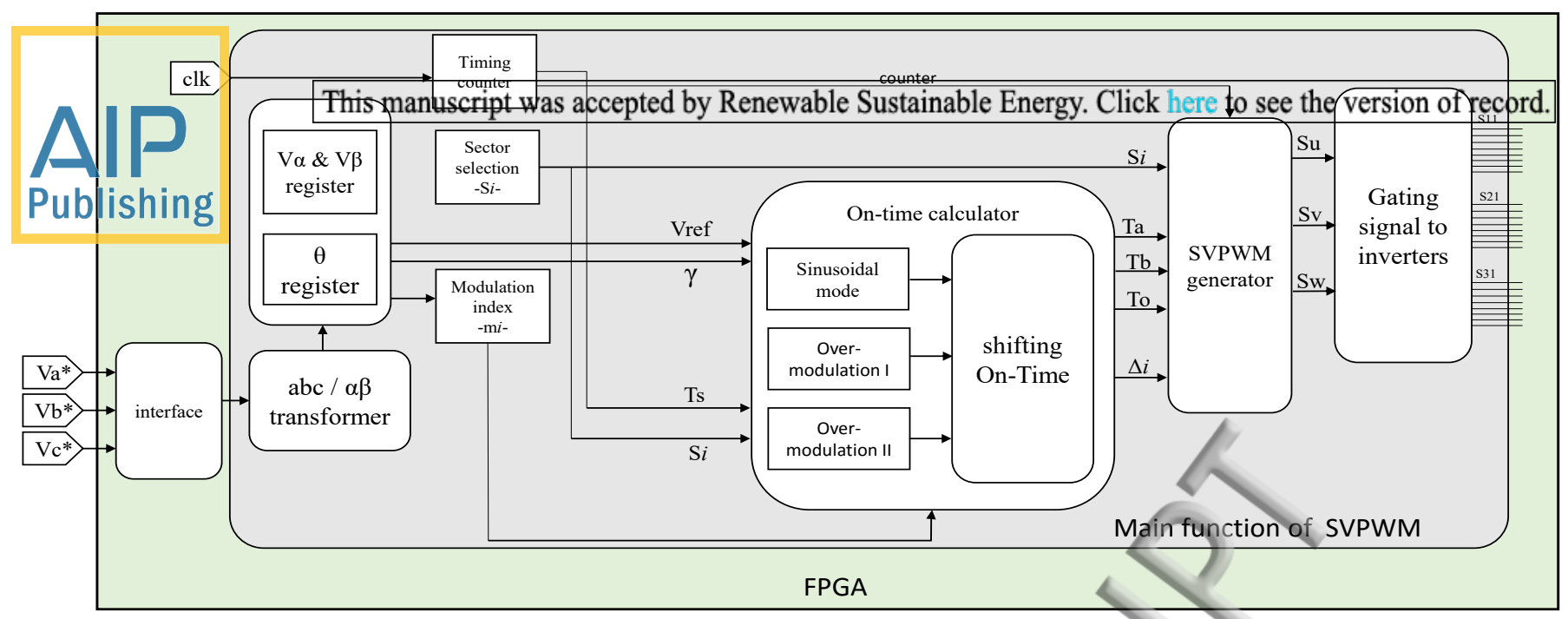

(a)

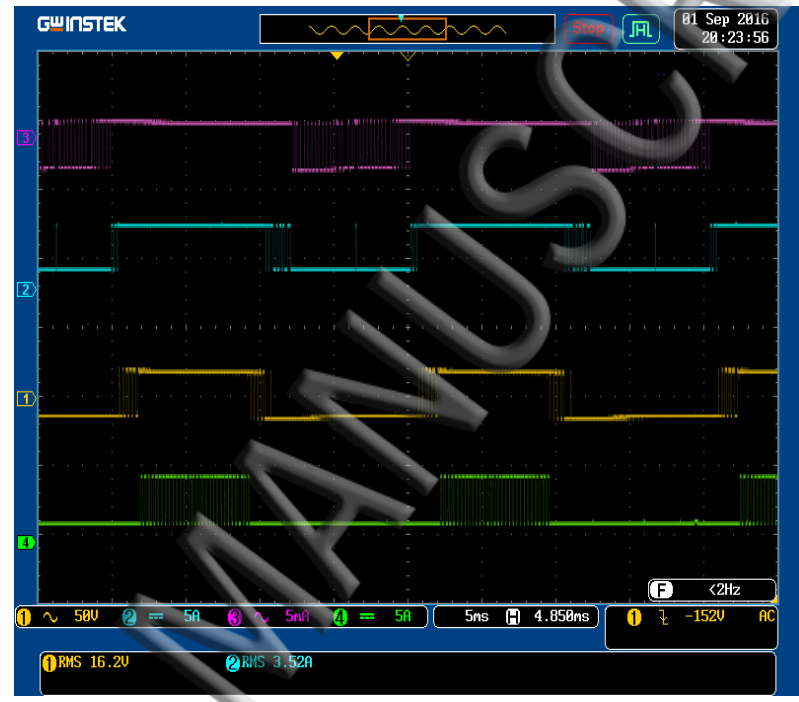

(b)

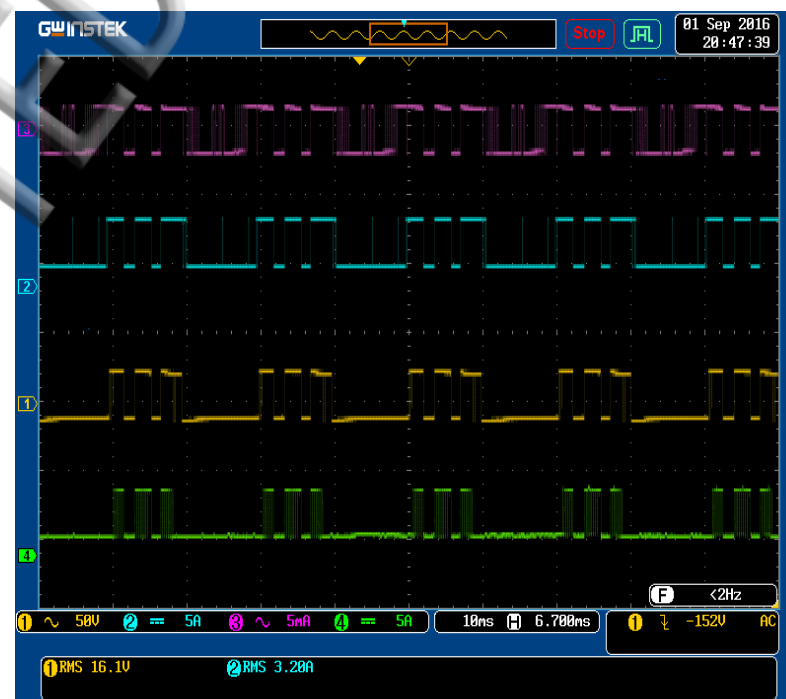

(c)

FIG. 14: (a): Block diagram of the proposed VHDL code for SVPWM; the experimental inverter pulses [S11-S14] (b): $\mathrm{mi}=0.82 ;(\mathrm{c}): \mathrm{mi}=0.92$. 

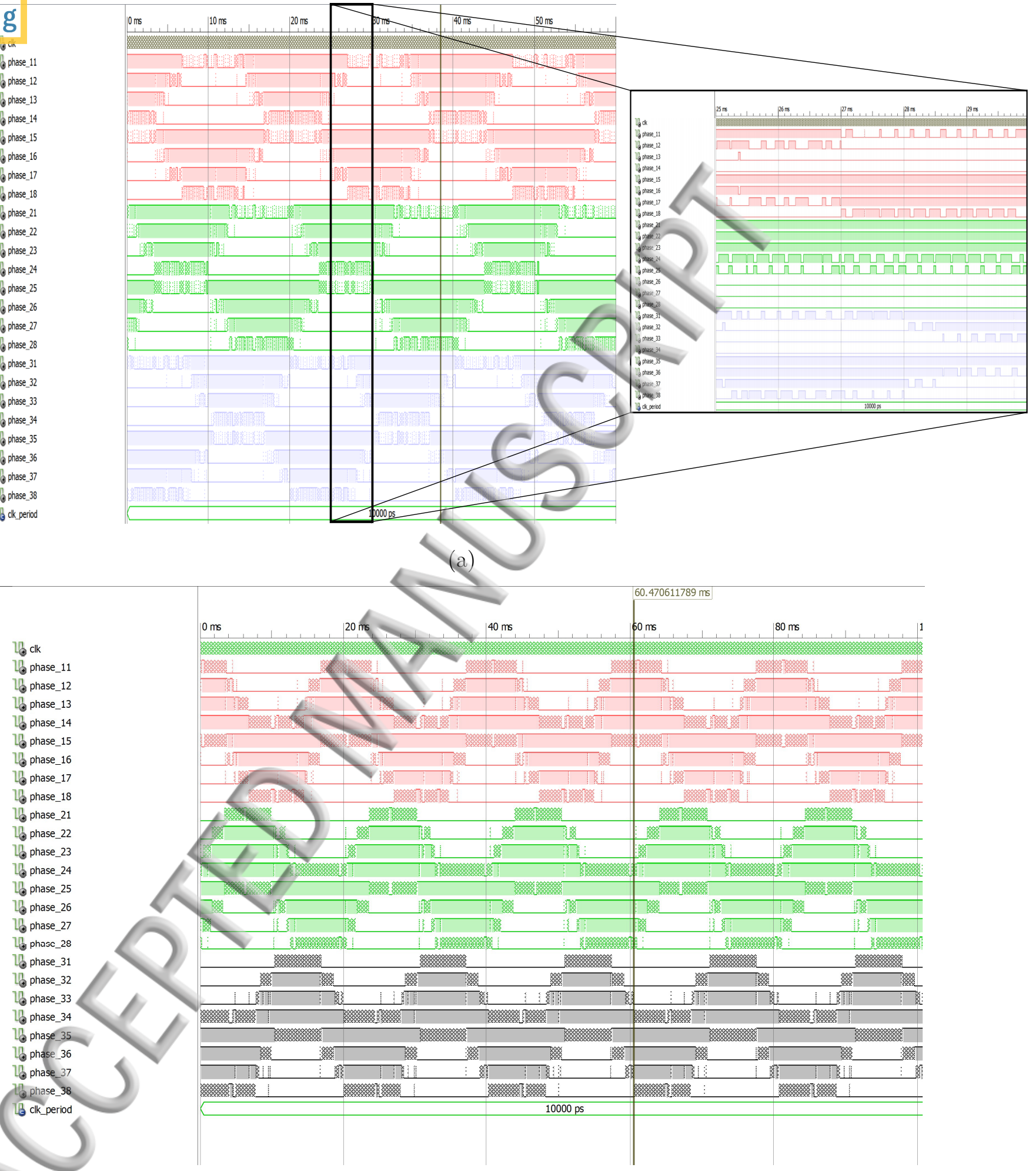

(b)

FIG. 15: The simulated 24-pulses gate control signals generated by SVPWM for (a): cascaded inverter; (b): diode clamped inverter. 
Publishing The experimental inverter pulses [S11-S14] are presented in Figs. 14(b) and 14(c) for $m i=$

$0.82 ; m i=0.92$. The computation process is similar for each reference vector located in any of the 96 sub-triangles; nevertheless, the resultant switching states, switching sequences of the voltage vectors, are different in each sub-triangle. All the functional blocks in Fig. 14(a) are described using VHDL coding. Fig. 15 presents the simulated 24-pulses gate control signals generated by SVPWM algorithm for cascaded inverter Fig. 15(a) and diode clamped inverter Fig. 15(b) by Xilinx ISE. To store the switching sequences and the switching states, look up tables (LUTs) are used. Different criteria are considered, for example, simplicity, flexibility and computation accuracy, while designing the VHDL code. The VHDL code includes a number of computational blocks, such as, sector identifier, switching state selector and on-time calculator. The proposed work, takes into account some key design measures in order to simplify hardware design and enhance calculation precision.

\subsection{Hardware in the loop implementation (HIL)}

Traditionally, industrial control tests are performed directly on physical equipment (eg, a production line), or on the entire system, or on a laboratory test-bench. These approaches have the advantage to be realistic, but they could be very costly, unsuccessful or even dangerous. The HIL test perfectly remedies to these disadvantages. In this case, the physical installation under test is replaced by a computer model, executed in real time on a simulator equipped with inputs/outputs (I/O) interfacing with the systems control and other equipments. This simulator can thus accurately reproduce the controlled system and its dynamics, as well as its instrumentation (sensors/actuators), to test their closed-loop interactions without going through a real system. The real-time simulation of power electronics systems remains one of the most ambitious challenges of simulation with hardware in the loop (HLL). Input/output capabilities for PWM capture, closed loop simulation latency, matched resolution of coupled switches and fault injection at all levels of a complex system of power electronics, are all examples illustrating the complexity of this evolving sector ${ }^{38,39}$. The hardware implementation is performed in the Xilinx (XC5VLX50-1FFG676) FPGA circuit and Simulink via Ethernet cable (Fig. 16). The FPGA in the Loop (FIL) generates the PWM signals, used to control the three phase inverter in Simulink. As it can be seen from Fig. 16, the main control targets are attained. 
Publishing whe waveform of the output voltage is very close to that simulated in Fig. 13. The results 327 of the co-simulation obtained show the correct practice of the VHDL codes developed and confirm the possibility of a practical implementation of the digital controller designed for the system.

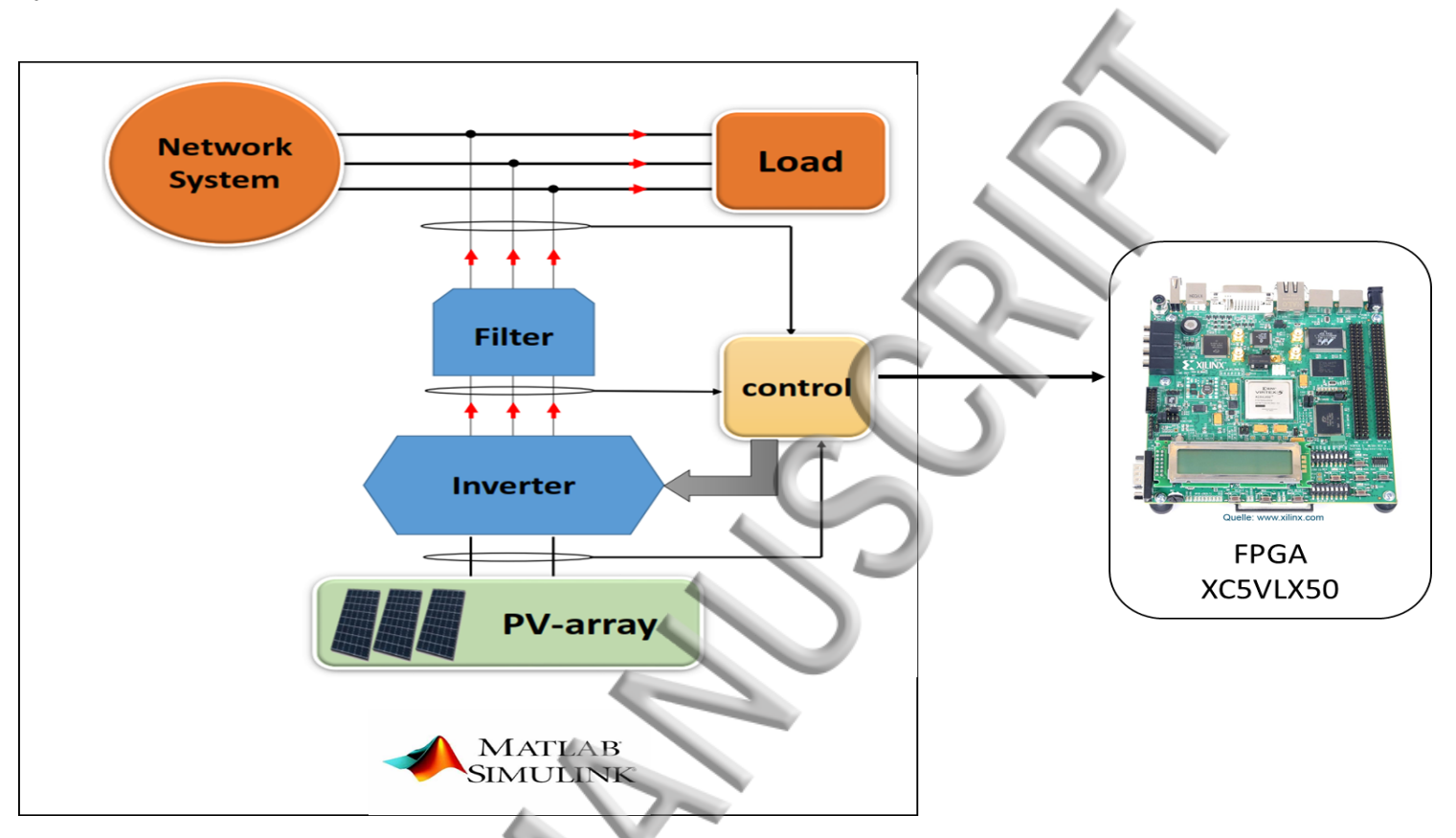

FIG. 16: Schematic prototype of the hardware in the loop for the five-level 3-phase inverter with Matlab/FPGA.
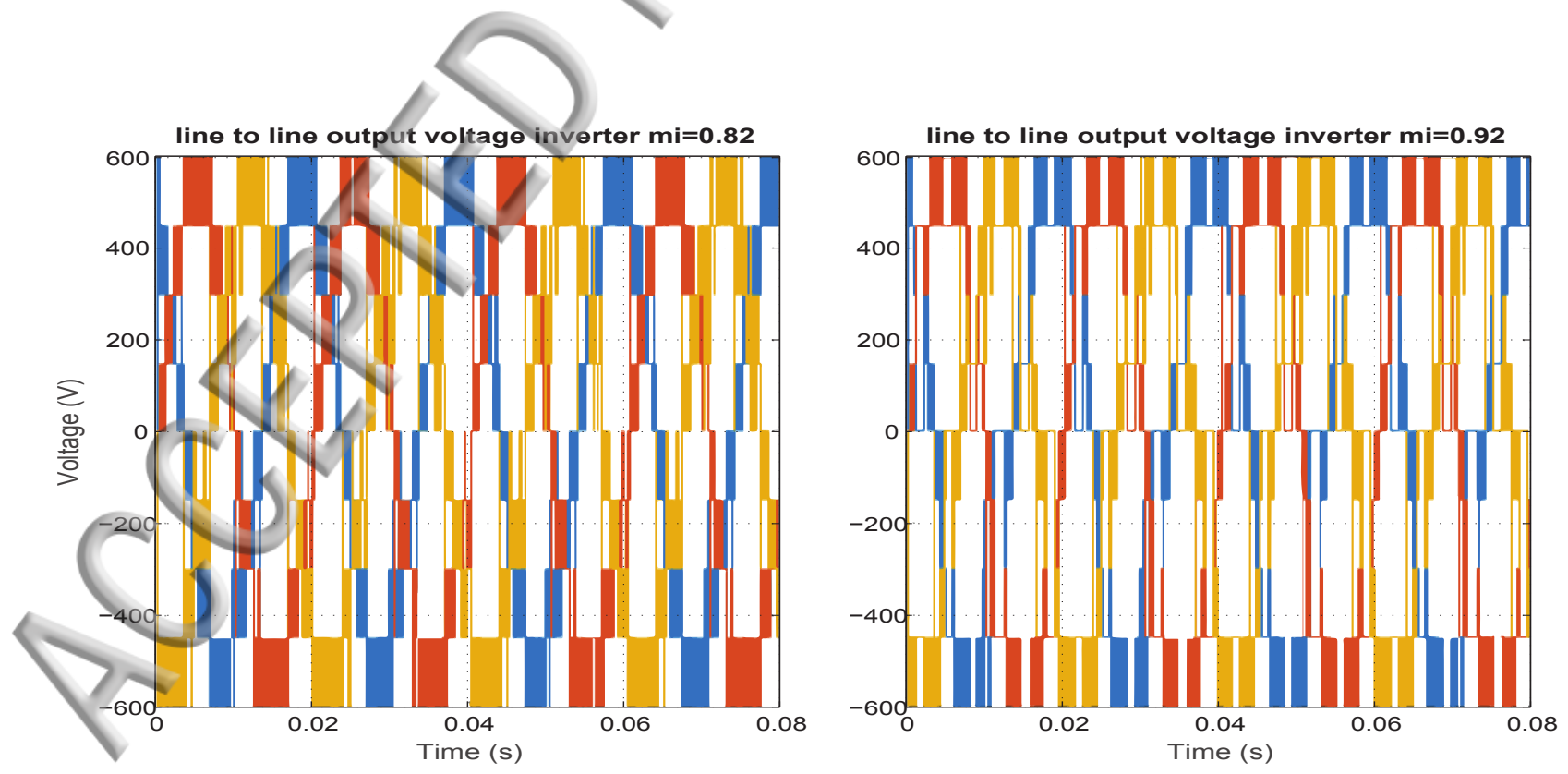

FIG. 17: The hardware in the loop results for the five-level 3-phase inverter with Matlab/FPGA. 


\section{Requirements for active and reactive power injected}

One of the objectives to achieve by the inverter is the control of the current from the PV arrays and the power injected into the network according to the appropriate standards. These advanced features can be provided by next-generation photovoltaic systems and will be improved in the future to ensure efficient and reliable use of photovoltaic systems. On this basis, active and reactive power injection strategies for three-phase PV systems are explored in this paper.

\subsubsection{The $P Q$ theory}

From the instantaneous line current and phase voltage, the instantaneous real power $\mathrm{P}$ and the instantaneous imaginary power $\mathrm{Q}$ are defined on the $(d-q)$ axes $\mathrm{as}^{40}$ :

$$
\left[\begin{array}{c}
P_{g} \\
Q_{g}
\end{array}\right]=\left[\begin{array}{cc}
v_{g_{-}} & v_{g_{-} q} \\
-v_{g_{-} q} & v_{g_{-}} d
\end{array}\right]\left[\begin{array}{c}
i_{2_{-} d} \\
i_{2_{-} q}
\end{array}\right]
$$

In the following description, the $(d-q)$ current will be set as function of the voltages and the real and imaginary power $\mathrm{P}$ and $\mathrm{Q}$. This is exceptionally appropriate to better clarify the physical significance of the power characterized in P-Q hypothesis. Therefore, it is conceivable to write:

$$
\left[\begin{array}{l}
\hat{i}_{2_{-} d} \\
\hat{i}_{2_{-} q}
\end{array}\right]=\frac{1}{V_{g_{-} d}{ }^{2}+V_{g_{-} q}{ }^{2}} \times\left[\begin{array}{cc}
v_{g_{-} d} & v_{g_{-} q} \\
-v_{g_{-} q} & v_{g_{-} d}
\end{array}\right] \times\left[\begin{array}{c}
P_{g} \\
Q_{g}
\end{array}\right] .
$$

\subsubsection{Output LCL filter}

The inverter, which is the key component of the grid connected PV system, is associated to the grid through an LCL filter arrangement. The switching frequency should be much higher than the grid frequency and the parasitic parameters are ignored ${ }^{41,42}$. In view of this supposition, the current and voltage in the system can be investigated without consideration of the high-frequency components. In the steady state, the grid phase currents $I_{2 a}, I_{2 b}$, and $I_{2 c}$ are controlled to be in phase with the consistent grid phase voltages $V_{g a}, V_{g b}$, and $V_{g c}$ which are given in equation (8): 


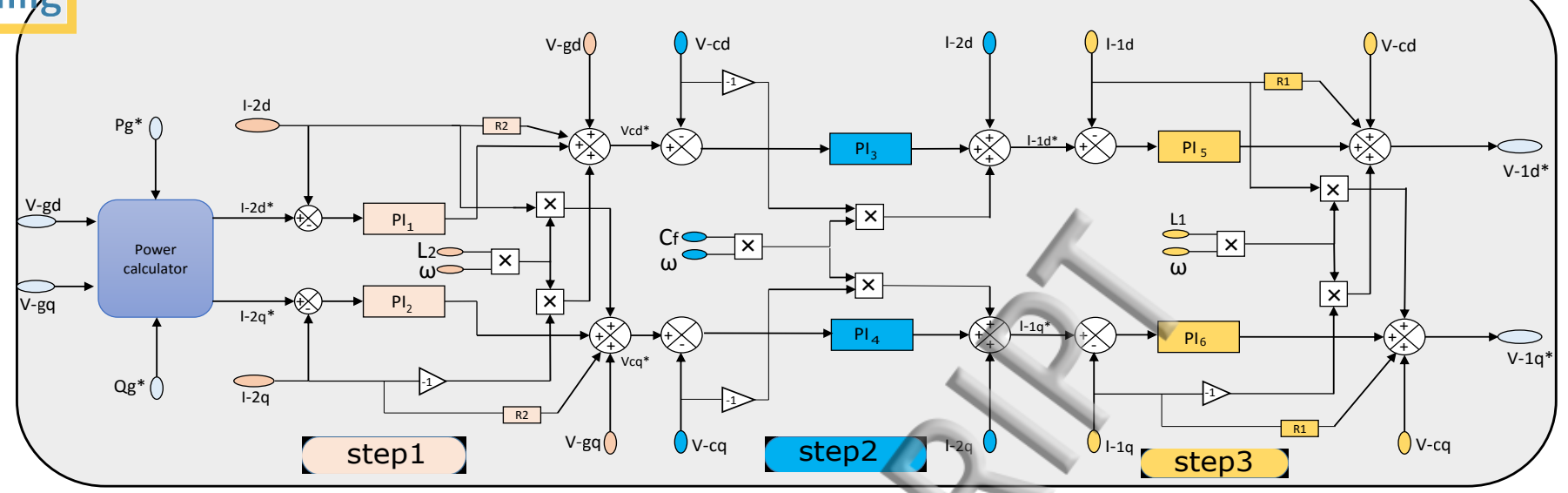

FIG. 18: Block diagram of a three phase grid-connected PV inverter control.

$$
\left[\begin{array}{c}
V_{g a} \\
V_{g b} \\
V_{g c}
\end{array}\right]=\left[\begin{array}{c}
V_{m} \cos (w t) \\
V_{m} \cos (w t-2 \pi / 3) \\
V m \cos (w t+2 \pi / 3)
\end{array}\right]
$$

where $w$ and $V_{m}$ are the angular frequency and the amplitude of the phase voltage, respectively. The equations describing the voltage and current of the three phase LCL filter are:

\subsubsection{Feedback linearization control for the PV inverter systems}

where $k$ is the phase number equal to $\{1,2,3\}$,

A three-phase system is modelled by a current injector with its power regulation. The control system regulates the power injected by the PV system into the connection point as a function of the temperature and irradiance. The purpose of this control is to impose the active and reactive powers injected by the PV system at the connection point of the distribution network, by defining the desired set point values $\mathrm{P}$ and $\mathrm{Q}$. In reality, the active power $\mathrm{P}$ is set by the MPPT module of the PV system and the reactive power $\mathrm{Q}$ is zero. 


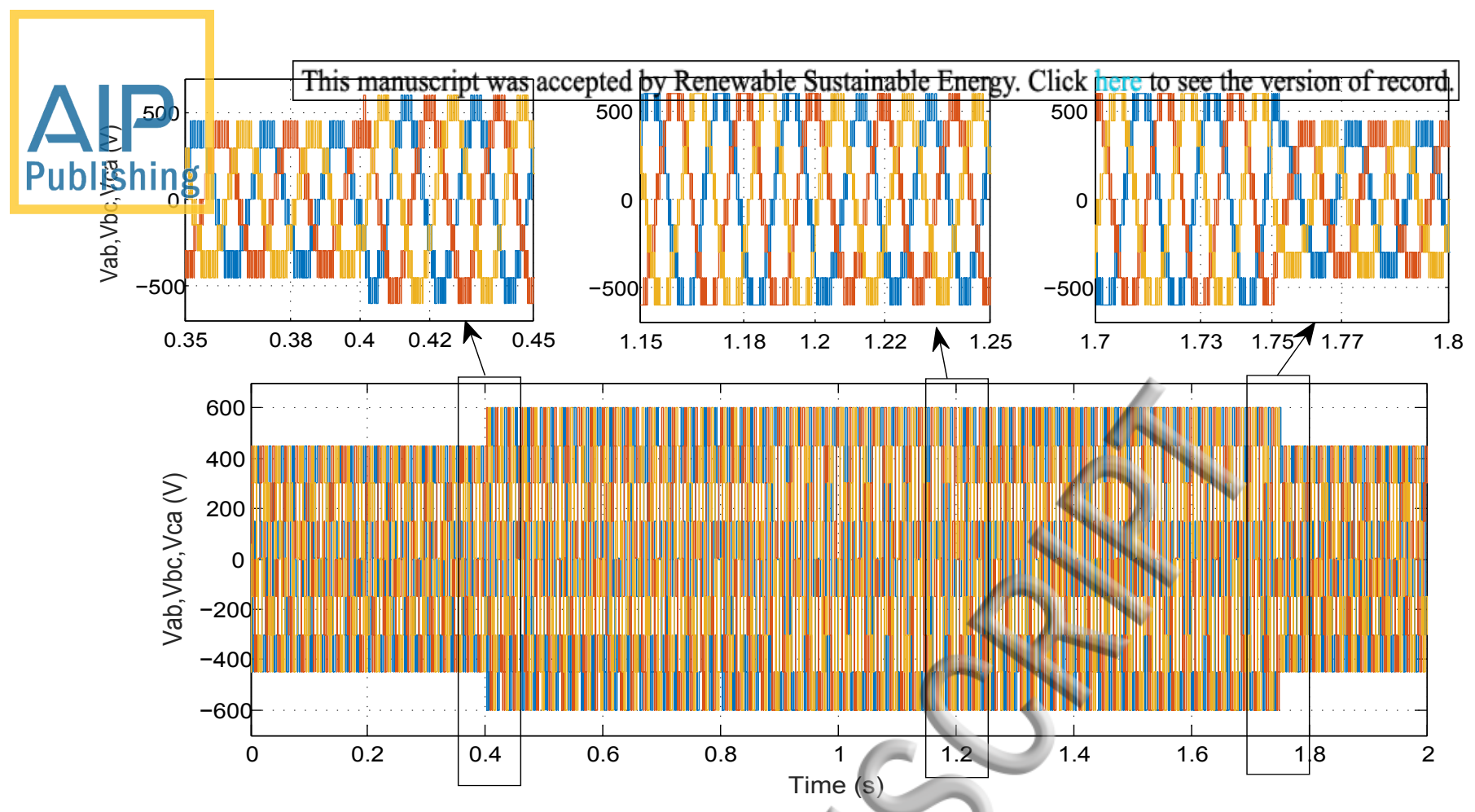

(a)
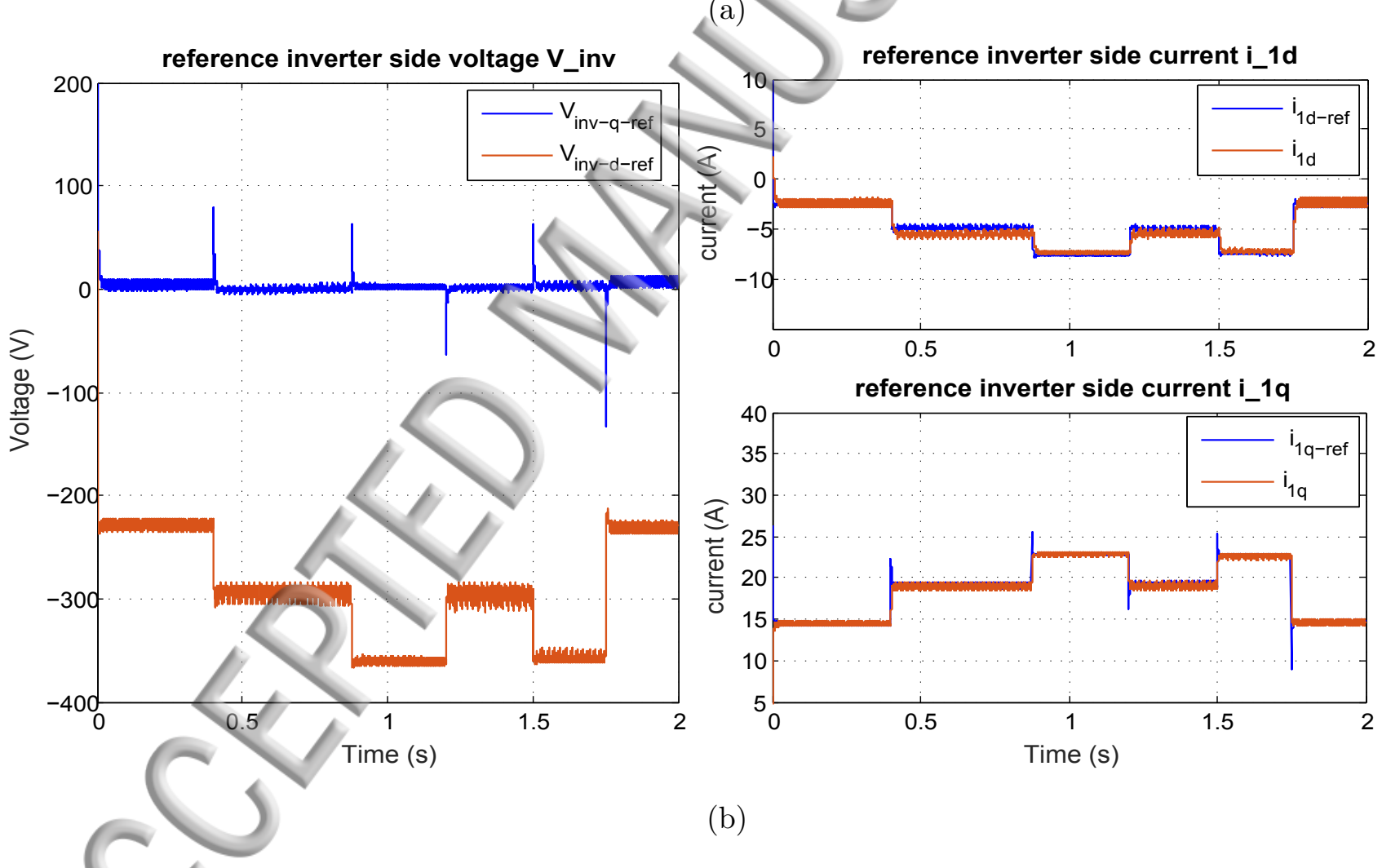

(b)

FIG. 19: The inverter voltages and currents obtained with direct power control.

Moreover, this imposition of power will directly participates through the regulation of the DC bus, to the selection of the active current (Id) sent to the network. By measuring the currents and the three-phase voltages at the connection point, it is possible to determine the 
Publishing ents to be injected. The process of this model is described in Fig. 18. From the voltages 372 and currents measured at the grid connection point, the active and reactive powers are current of the inverter and of the power limit of the DC source.

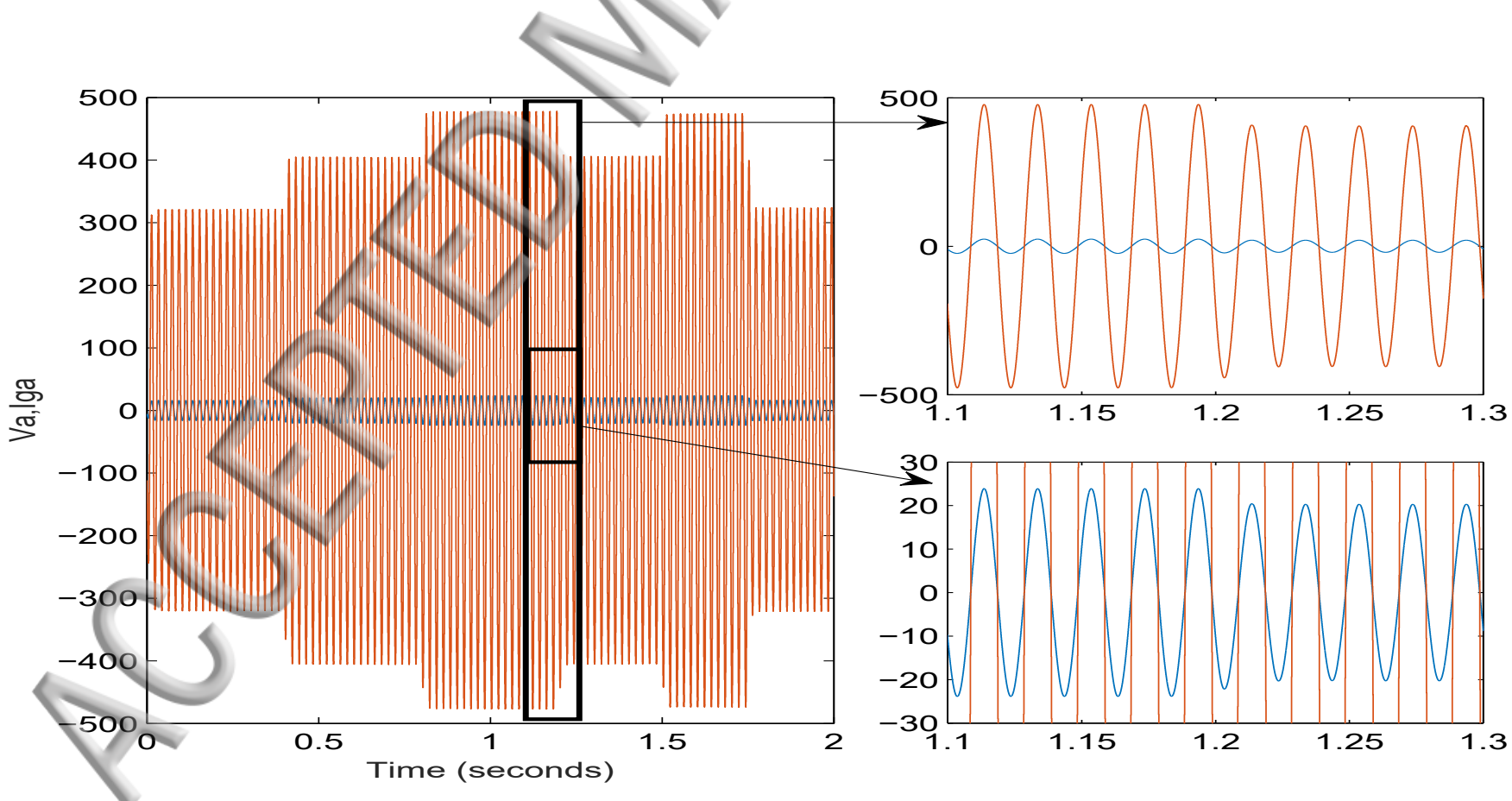
determined. These powers are controlled by a simple Proportional-Integral type correctors. Where $V_{d}$ and $V_{q}$ are the direct and quadrature components of the voltage, measured at the point of common coupling (PCC), in the Park reference. $I_{d}$ and $I_{q}$ are the direct and quadrature components of the reference product current by the PV system on the network to which it is connected. $\mathrm{P}$ and $\mathrm{Q}$ are the reference powers of the PV system. Therefore these currents depend on the power demands as well as on the voltage measured at the point of connection. A PLL is used to synchronize the Park transformation to the pulse of the measured voltage across the network. Thus, as shown in Figs. 19(a) and 19(b), in steady state, the quadratic component $V_{q}$ is zero and the direct component $V_{d}$ at the output of the Park transformation is an image of the amplitude of the measured voltage. These currents are then converted into the three-phase reference. The amplitude and the phase shift of the currents injected into the network, shown in Fig. 20, will thus regulate the powers at their set value. The limit for the component $I_{d}$ is chosen as a function of the maximum output

FIG. 20: The phase angle between current injected and grid voltage at point of common coupling (PCC). 


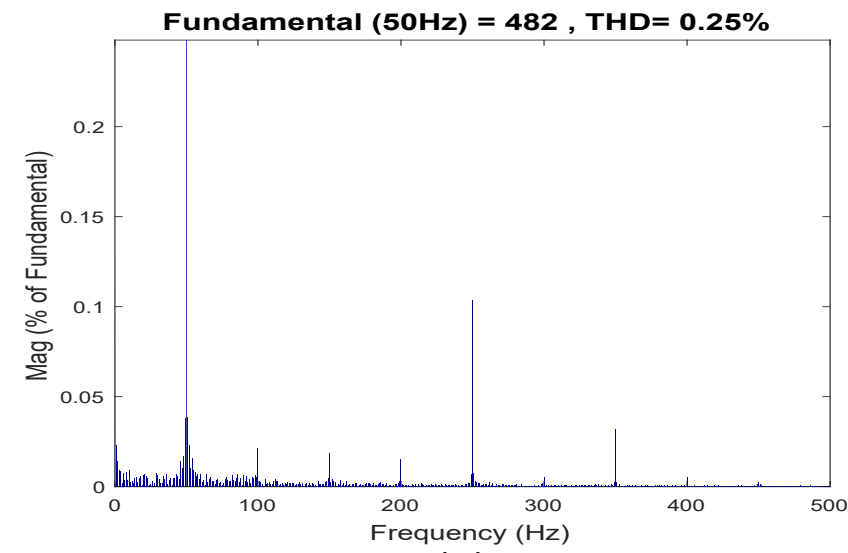

(a)

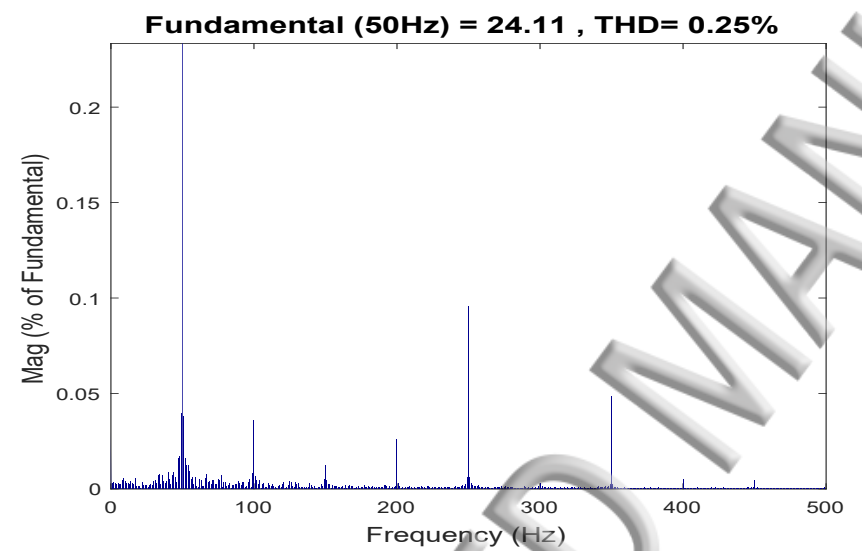

(c)

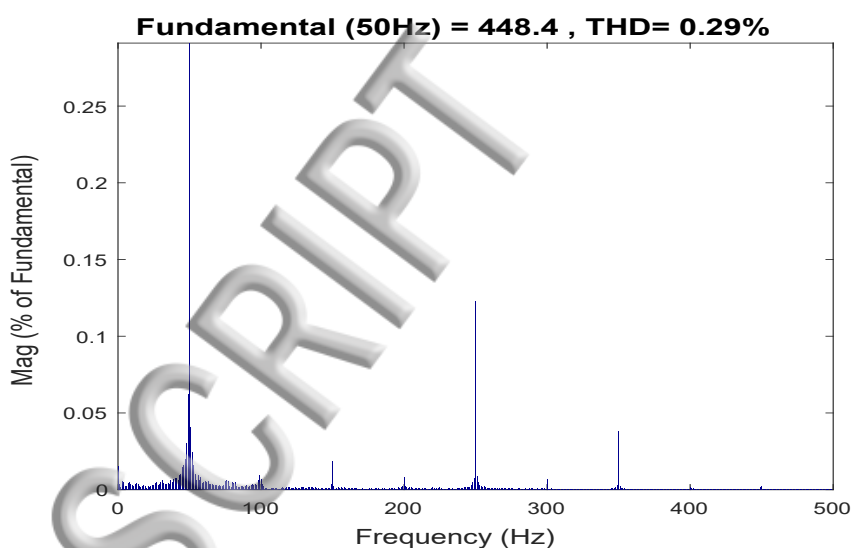

(b)

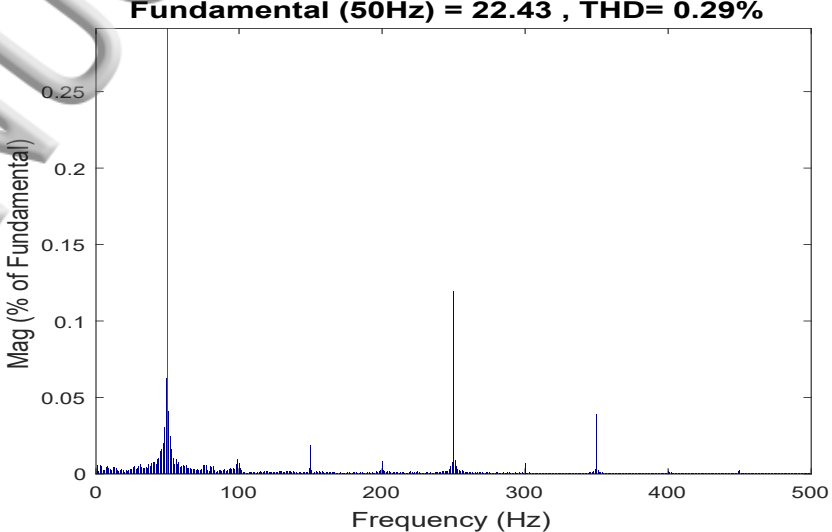

(d)

FIG. 21: The THD measurement for five-level inverter cascade (a):voltage,(c):current and diode clamped (b): voltage, (d):current.

The THD measurement for both five-level inverters is shown in Fig. 21. The output THD voltage for cascade inverter is presented in Fig. 21(a) and the output THD voltage for diode clamped inverter is presented in Fig. 21(b). The output THD current for cascade and diode clamped are presented respectively in Fig. 21(c) and Fig. 21(d). The simulation results in Fig. 21 demonstrate that the SVPWM based multilevel system has an output line-to-line voltage and current with a very low THD. When the modulation index is increased, better performance can be achieved. This demonstrates that the proposed scheme can reduce the THD which is an necessary condition in grid connected PV systems. 


\section{CONCLUSION}

In this paper, a control structure for grid connected photovoltaic systems using two different three-phase multilevel inverter topologies has been presented. The studied topologies comprise two basic groups based on the decoupling method: DCI and cascade inverter topologies. These topologies are presented, compared and evaluated on the basis of PSOMPPT technique, component ratings, harmonic distortion, cost, advantages and disadvantages. A study of the PV generators under different scenarios of partial shading was also carried out. In addition, the benefits of the SVPWM control scheme have been demonstrated. The different control blocks of the control structure including PSO-MPPT and SVPWM algorithm have been implemented based on FPGA chip with low resource consumption and reduced execution time than conventional methods. The use of a FPGA-circuit in the design of the embedded controller reduces complexity, increases speed and adds flexibility to the design of the control circuit. The co-simulation Simulink/Xilinx based on the Hardware In the Loop approach was demonstrated to shew the correct operation of the developed FPGA implementation and to confirm the prospect of a practical implementation of the designed digital controller scheme in a grid connected PV system. The proposed control structure for grid connected photovoltaic systems using a PSO-MPPT and the two multilevel inverter topologies is a good solution to optimize the energy yield from PV generators and to enhance the quality of the energy injected into the grid.

\section{REFERENCES}

${ }^{1}$ HL Zhang, Jan Baeyens, J Degrève, and G Cacères, "Concentrated solar power plants: Review and design methodology," Renewable and Sustainable Energy Reviews 22, 466-481 (2013).

${ }^{2}$ Fanbo He, Zhengming Zhao, and Liqiang Yuan, "Impact of inverter configuration on energy cost of grid-connected photovoltaic systems," Renewable energy 41, 328-335 (2012). ${ }^{3}$ G Cacères, N Anrique, Aymeric Girard, Jan Degrève, Jan Baeyens, and HL Zhang, "Performance of molten salt solar power towers in chile," Journal of Renewable and Sustainable Energy 5, 053142 (2013). 
Publishinfigoubhagya Kumar Dash, Savita Nema, RK Nema, and Deepak Verma, "A comprehensive assessment of maximum power point tracking techniques under uniform and non-uniform irradiance and its impact on photovoltaic systems: A review," Journal of Renewable and Sustainable Energy 7, 063113 (2015).

${ }^{5}$ Huili Zhang, Jan Baeyens, Gustavo Cacères, Jan Degrève, and Yongqin Lv, "Thermal energy storage: Recent developments and practical aspects," Progress in Energy and Combustion Science 53, 1-40 (2016).

${ }^{6}$ Peter Christoff, "The promissory note: Cop 21 and the paris climate agreement," Environmental Politics 25, 765-787 (2016).

${ }^{7}$ Subhadeep Bhattacharjee and Barnam Jyoti Saharia, "A comparative study on converter topologies for maximum power point tracking application in photovoltaic generation," Journal of Renewable and Sustainable Energy 6, 053140 (2014).

${ }^{8}$ Soeren Baekhoej Kjaer, John K Pedersen, and Frede Blaabjerg, "A review of singlephase grid-connected inverters for photovoltaic modules," IEEE transactions on industry applications 41, 1292-1306 (2005).

${ }^{9}$ Mohammad Barghi Latran and Ahmet Teke, "Investigation of multilevel multifunctional grid connected inverter topologies and control strategies used in photovoltaic systems," Renewable and Sustainable Energy Reviews 42, 361-376 (2015).

${ }^{10}$ Suneel Raju Pendem and Suresh Mikkili, "Modelling and performance assessment of pv array topologies under partial shading conditions to mitigate the mismatching power losses," Solar Energy 160, 303-321 (2018).

${ }^{11} \mathrm{~F}$. Belhachat and C. Larbes, "Modeling, analysis and comparison of solar photovoltaic array configurations under partial shading conditions," Solar Energy 120, 399 - 418 (2015).

${ }^{12}$ Majid Horoufiany and Reza Ghandehari, "Optimization of the sudoku based reconfiguration technique for pv arrays power enhancement under mutual shading conditions," Solar Energy 159, 1037-1046 (2018).

${ }^{13} \mathrm{~L}$ Hassaine, E OLias, J Quintero, and V Salas, "Overview of power inverter topologies and control structures for grid connected photovoltaic systems," Renewable and Sustainable Energy Reviews 30, 796-807 (2014).

${ }^{14}$ Shimi Sudha Letha, Tilak Thakur, and Jagdish Kumar, "Harmonic elimination of a photovoltaic based cascaded h-bridge multilevel inverter using pso (particle swarm optimization) for induction motor drive," Energy 107, 335-346 (2016). 
Publishithegngin Ozdemir, Sule Ozdemir, and Leon M Tolbert, "Fundamental-frequency-modulated

457 six-level diode-clamped multilevel inverter for three-phase stand-alone photovoltaic system," IEEE Transactions on Industrial Electronics 56, 4407-4415 (2009).

${ }^{16}$ Enrique Romero-Cadaval, Giovanni Spagnuolo, Leopoldo Garcia Franquelo, Carlos Andres Ramos-Paja, Teuvo Suntio, and Weidong Michael Xiao, "Grid-connected photovoltaic generation plants: Components and operation," IEEE Industrial Electronics Magazine 7, 6-20 (2013).

${ }^{17}$ Yi-Hung Liao and Ching-Ming Lai, "Newly-constructed simplified single-phase multistring multilevel inverter topology for distributed energy resources," IEEE Transactions on Power Electronics 26, 2386-2392 (2011).

${ }^{18}$ Sairaj V Dhople, Jonathan L Ehlmann, Ali Davoudi, and Patrick L Chapman, "Multipleinput boost converter to minimize power losses due to partial shading in photovoltaic modules," in Energy Conversion Congress and Exposition (ECCE), 2010 IEEE (IEEE, 2010) pp. 2633-2636.

${ }^{19}$ Eduardo Roman, Ricardo Alonso, Pedro Ibañez, Sabino Elorduizapatarietxe, and Damián Goitia, "Intelligent pv module for grid-connected pv systems," IEEE Transactions on Industrial electronics 53, 1066-1073 (2006).

${ }^{20}$ Weimin $\mathrm{Wu}$, Junhao Ji, and Frede Blaabjerg, "Aalborg inverter-a new type of buck in buck, boost in boost grid-tied inverter," IEEE Transactions on power electronics 30, 47844793 (2015).

${ }^{21}$ Giovanna Adinolfi, Giorgio Graditi, Pierluigi Siano, and Antonio Piccolo, "Multiobjective optimal design of photovoltaic synchronous boost converters assessing efficiency, reliability, and cost savings," IEEE Transactions on Industrial Informatics 11, 1038-1048 (2015).

${ }^{22}$ Dipankar Debnath and Kishore Chatterjee, "Two-stage solar photovoltaic-based standalone scheme having battery as energy storage element for rural deployment," IEEE Transactions on Industrial Electronics 62, 4148-4157 (2015).

${ }^{23} \mathrm{~F}$ Spertino and G Graditi, "Power conditioning units in grid-connected photovoltaic systems: A comparison with different technologies and wide range of power ratings," Solar Energy 108, 219-229 (2014).

${ }^{24}$ Monirul Islam and Saad Mekhilef, "An improved transformerless grid connected photovoltaic inverter with reduced leakage current," Energy Conversion and Management 88, 854-862 (2014). 
Publishîng 489 partial shading effects in photovoltaic arrays," IEEE Journal of Photovoltaics 2, 532-546 (2012).

${ }^{26}$ Kashif Ishaque, Zainal Salam, et al., "A comprehensive matlab simulink pv system simulator with partial shading capability based on two-diode model," Solar energy 85, 2217-2227 (2011).

${ }^{27}$ Karim Kaced, Cherif Larbes, Naeem Ramzan, Moussaab Bounabi, and Zine elabadine Dahmane, "Bat algorithm based maximum power point tracking for photovoltaic system under partial shading conditions," Solar Energy 158, 490 - 503(2017).

${ }^{28}$ Jubaer Ahmed and Zainal Salam, "A critical evaluation on maximum power point tracking methods for partial shading in pv systems," Renewable and Sustainable Energy Reviews 47, 933-953 (2015).

${ }^{29}$ Sundharajan Venkatesan and Manimaran Saravanan, "Simulation and experimental validation of new mppt algorithm with direct control method for pv application," Journal of Renewable and Sustainable Energy 8, 043503 (2016).

${ }^{30}$ Lulin Yin, Songsen Yu, Xing Zhang, and Yong Tang, "Simple adaptive incremental conductance mppt algorithm using improved control model," Journal of Renewable and Sustainable Energy 9, 065501 (2017).

${ }^{31}$ Ahmed IM Ali, Mahmoud A Sayed, and Essam EM Mohamed, "Modified efficient perturb and observe maximum power point tracking technique for grid-tied pv system," International Journal of Electrical Power \& Energy Systems 99, 192-202 (2018).

${ }^{32}$ R. Eberhart and J. Kennedy, "A new optimizer using particle swarm theory," in Micro Machine and Human Science, 1995. MHS '95., Proceedings of the Sixth International Symposium on (1995) pp. 39-43.

${ }^{33}$ N. Prabaharan and K. Palanisamy, "Analysis and integration of multilevel inverter configuration with boost converters in a photovoltaic system," Energy Conversion and Management 128, 327 - 342 (2016).

${ }^{34}$ P. M. Bhagwat and V. R. Stefanovic, "Generalized structure of a multilevel pwm inverter," IEEE Transactions on Industry Applications IA-19, 1057-1069 (1983).

${ }^{35}$ Amit Kumar Gupta and Ashwin M Khambadkone, "A general space vector pwm algorithm for multilevel inverters, including operation in overmodulation range," Power Electronics, IEEE Transactions on 22, 517-526 (2007). 
Valan Rajkumar and PS Manoharan, "Fpga based multilevel cascaded inverters with ${ }_{521}$ svpwm algorithm for photovoltaic system," Solar Energy 87, 229-245 (2013).

${ }^{37}$ Yi Deng, Yebin Wang, Koon Hoo Teo, and Ronald G Harley, "A simplified space vector modulation scheme for multilevel converters," Power Electronics, IEEE Transactions on 31, 1873-1886 (2016).

${ }^{38}$ Mamianja Rakotozafy, Philippe Poure, Shahrokh Saadate, Cédric Bordas, and Loic Leclere, "Real-time digital simulation of power electronies systems with neutral point piloted multilevel inverter using fpga," Electric Power Systems Research 81, 687 - 698 (2011).

${ }^{39}$ Alberto Sanchez, Angel De Castro, and Javier Garrido, 'A comparison of simulation and hardware-in-the-loop alternatives for digital control of power converters," Industrial Informatics, IEEE Transactions on 8, 491-500 (2012).

${ }^{40}$ Amirnaser Yazdani and Reza Iravani, Voltage-sourced converters in power systems: modeling, control, and applications (John Wiley \& Sons, 2010).

${ }^{41}$ Xianwen Bao, Fang Zhuo, Yuan Tian, and Peixuan Tan, "Simplified feedback linearization control of three-phase photovoltaic inverter with an lcl filter," Power Electronics, IEEE Transactions on 28, 2739-2752 (2013)

${ }^{42}$ Sebastian Rivera, Samir Kouro, Bin Wu, Salvador Alepuz, Mariusz Malinowski, Patricio Cortes, and Jose Rodriguez, "Multilevel direct power control-a generalized approach for grid-tied multilevel converter applications," Power Electronics, IEEE Transactions on 29, $5592-5604(2014)$. 